\title{
Small-Angle X-Ray Scattering
} Studies of Microvoids in Amorphous-Silicon-Based Semiconductors

\section{Final Subcontract Report}

1 February 1991 - 31 January 1994

D. L. Williamson, S. J. Jones, Y. Chen Colorado School of Mines

Golden, Colorado

NREL technical monitor: W. Luft

National Renewable Energy Laboratory $40 \mathrm{CPC}$ 1617 Cole Boulevard Golden, Colorado 80401-3393

A national laboratory of the U.S. Department of Energy Managed by Midwest Research Institute for the U.S. Department of Energy under contract No. DE-AC02-83CH10093

Prepared under Subcontract No. XG-1-10063-3 


\section{NOTICE}

NOTICE: This report was prepared as an account of work sponsored by an agency of the United States government. Neither the United States government nor any agency thereof, nor any of their employees, makes any warranty, express or implied, or assumes any legal liability or responsibility for the accuracy, completeness, or usefulness of any information, apparatus, product, or process disclosed, or represents that its use would not infringe privalely owned rights. Reference herein to any specific commercial product, process, or senvice by trade name, trademark, manufacturer, or otherwise does not necessarily constitute or imply its endorsement, recommendation, or favoring by the United States government or any agency thereof. The views and opinions of authors expressed herein do not necessarily state or reflect those of the United States government or any agency thereof.

Printed in the United States of America

Available from:

National Technical Information Service

U.S. Department of Commerce

5285 Port Royal Road

Springfield, VA 22161

Price: Microfiche A01

Printed Copy $\mathrm{AO}$

Codes are used for pricing all publications. The code is determined by the number of pages in the publication. Information pertaining to the pricing codes can be found in the current issue of the following publications which are generally available in most libraries: Energy Research Abstracts (ERA); Government Reports Announcements and Index (GRA and I); Scientific and Technical Abstract Reports (STAR); and publication NTIS-PR-360 available trom NTIS at the above address. 


\section{DISCLAIMER}

Portions of this document may be illegible electronic image products. Images are produced from the best available original document. 


\section{EXECUTIVE SUMMARY}

\subsection{OBJECTIVES}

Our general objectives during this three-year research project were to provide new details of the microstructure for the size scale from about 1 to $30 \mathrm{~nm}$ in high-quality a$\mathrm{Si}: \mathrm{H}$ and related alloys prepared by current state-of-the-art deposition methods as well as by new and emerging deposition technologies and thereby help determine the role of microvoids and other density fluctuations in controlling the opto-electronic properties.

More specifically, the objectives were to determine whether the presence of microstructure as detected by small-angle $x$-ray scattering (SAXS) (1) limits the photovoltaic properties of device-quality a-Si:H, (2) plays a role in determining the photo-stability of a-Si:H, and (3) is responsible for degradation of the photovoltaic properties due to alloying with $\mathrm{Ge}, \mathrm{C}$ and other constituents. The approach involved collaboration with several groups that supplied relevant systematic sets of samples and the associated opto-electronic data to help address these issues. Since the SAXS technique had not been a standard characterization technique for thin-film materials, and was set up at CSM with support by NREL, an underlying 4th objective of the project involved considerable development of the method with regard to identifying and interpreting various scattering contributions to the signals in the small-angle regime, standardizing the procedures, minimizing substrate influences and implementing improved data reduction and modeling methodology. Precise, highly reproducible, and accurate results were sought in order to allow useful, reliable, and sensitive comparisons of materials deposited under different conditions, by different methods, and by different systems that represent the same nominal method.

\subsection{CONCLUSIONS}

The SAXS technique as developed during this project is able to provide microstructural information not available from other methods and with a high degree of sensitivity. It is particularly sensitive to microvoids or H-rich microdomains and to the presence of oriented microstructure. The latter is readily associated with columnar-type growth and can even be observed in premature stages not detectable by transmission electron microscopy (TEM). New results related to alloy randomness have emerged from our ability to measure the diffuse scattering component of the SAXS. Flotation density measurements provided important complementary data. Specific conclusions from our three-year research program under NREL support are presented below relative to each of the three primary objectives as well as the fourth objective related to 
interpretation and development of the technique:

1) Role of SAXS-detected microstructure in photovoltaic properties of a-Si:H

(a) Extremely low microvoid volume fractions of the the order of $0.1 \%$ or less have now been established in films grown by a few groups, all by the PECVD method but with different conditions. All of these films show high-quality photovoltaic or optoelectronic behavior.

(b) a-Si:H p-i-n solar cells that contain more microstructure in the i-layer in the form of spherical or randomly-oriented microvoids and more $\mathrm{H}$ bonded as $\mathrm{Si}_{-} \mathrm{H}_{2}$ show lower initial efficiencies.

(c) Dilution during $70 \mathrm{MHz}$ PECVD growth with Ar causes enhanced microstructure in the form of microvoids. High Ar dilution leads to a highly oriented microstructure consistent with columnar-like growth. This behavior correlates with opto-electronic degradation. He dilution during PECVD growth allows increased deposition rates and reduced substrate temperatures while maintaining a low microvoid content and little or no oriented microstructure. Low defect densities and high photoconductivities are obtained in these He-diluted films. Although several ECRproduced films were made with and without $\mathrm{Xe}$ dilution, too many other parameters were varied to allow a conclusion on the effect of the Xe.

(d) Alternative deposition methods including hot-wire, ECR and RMS all yield a$\mathrm{Si}: \mathrm{H}$ films that show significant microvoid volume fractions ( 1 to $2 \%$ ) and yet high photo/dark conductivity ratios $\left(\sim 10^{5}\right)$ are observed. However solar cells have not yet been fabricated with these alternate deposition methods. Also, we have not yet obtained hot-wire material with the low $\mathrm{H}$ contents that show improved light stability.

\section{2) Role of SAXS-detected microstructure in the photostability of a-Si:H}

(a) a-Si:H p-i-n solar cells that contain more microstructure in the $\mathrm{i}$-layer in the form of very small voids and more $\mathrm{H}$ bonded as $\mathrm{Si}_{-} \mathrm{H}_{2}$ show more light-induced degradation. These results are in disagreement with suggestions by a Japanese group that more microstructure may yield more stable material.

(b) No change in SAXS could be detected after accelerated light-soaking of several a-Si:H films, thereby demonstrating that the Staebler-Wronski instability does not induce detectable changes in the microstructure such as void size increases or larger amounts of $\mathrm{H}$ within the voids. This result is not unexpected since the maximum number of defects involved in this important electronic effect is of the order of $10^{17} / \mathrm{cm}^{3}$. However, the microvoids or H-rich domains, as detected by SAXS, are at least this dense and therefore may play a direct role as the source of $\mathrm{H}$ or the location of 
the weak $\mathrm{Si}-\mathrm{H}$ bonds, proposed to be responsible for the light instability.

3) Role of SAXS-detected microstructure in the photovoltaic properties of alloys

(a) a-Si $\mathrm{Si}_{1-\mathrm{x}} \mathrm{Ge}_{\mathrm{x}}: \mathrm{H}$ alloys that show a microstructural transition corresponding to enhanced columnar-like growth above $\mathrm{x}=0.2$ have corresponding sharp degradations in opto-electronic properties above this same Ge content. This provides strong evidence that the increased low-density heterogeniety is directly responsible for the degradation.

(b) Solar cells made from $2-\mathrm{Si}_{1-x} \mathrm{Ge}_{x}: \mathrm{H}$ alloys have efficiencies that decrease smoothly with increasing $\mathrm{x}$ and SAXS from the corresponding alloys show little change in the microstructure until the $\mathrm{Ge}$ contents reach 31 and 41 at.\%. Thus, an obvious correlation of SAXS and initial cell efficiencies was not found. However, the cell lightsoaking stability was noticeably poorer for the latter two Ge contents.

(c) Angle-independent, random alloy (diffuse) scattering from $a-\mathrm{Si}_{1-x} \mathrm{Ge}_{\mathrm{x}}: \mathrm{H}$ alloys has been observed and identified. for the first time. A theoretical quadratic $x$ dependence is in good agreement with the observed dependence of the data on $x$ but the magnitude of the effect is much too strong. This enhanced diffuse scattering is direct evidence of short-range clustering of Ge and this effect may play an important role in the opto-electronic degradation due to short-range potential fluctuations.

(d) The SAXS-determined microstructures of a-Ge:H PECVD films prepared with variable electrode spacing and variable plasma power are the most homogeneous for those films with the best opto-electronic properties. a-Ge:H without oriented microstructure has not yet been observed for PECVD films but it has for sputterdeposited films. Ge-rich $a-\mathrm{Si}_{1-\mathrm{x}} \mathrm{Ge}_{\mathrm{x}}: \mathrm{H}$ alloys $(\mathrm{x} \simeq 0.7)$ have recently been produced at Harvard University that show SAXS signals approaching the best a-Si:H.

(e) $a-\mathrm{Si}_{1-x} \mathrm{Ge}_{\mathrm{x}}: \mathrm{H}: \mathrm{F}$ alloys prepared by PECVD from silane and germanium fluoride are microstructurally different from all the other PECVD alloys in that a larger fraction, of smaller scattering centers are present in a more randomly oriented array. Typically, this non-columnar-like microstructure yields better optoelectronic properties (see (a) above).

(f) A set of PECVD a-SiC:H alloys from Solarex shows strong SAXS due to microvoids that are so dense that they are correlated in position as evidenced by an interparticle interference effect in the SAXS curves. Such a microstructure is a likely limitation on the opto-electronic properties that are clearly in need of improvement.

(g) $\mathrm{a}-\mathrm{SiC}: \mathrm{H}$ alloys prepared by $\mathrm{RMS}$ all have a higher degree of oriented microstructure in contrast with PECVD materials which have randomly oriented or spherical microvoids. The RMS material has lower amounts of SAXS-detected 
microstructure and higher film densities for similar $C$ contents. The average void size is smaller in the PECVD films.

(h) A first set of $\mathrm{B}$-doped $\mathrm{a}-\mathrm{Si}: \mathrm{H}$ and $\mathrm{a}-\mathrm{SiC}: \mathrm{H}$ samples indicates small but systematic increases in the SAXS due to increased doping concentrations.

(i) Another approach to high bandgap material is being tested via Se alloying and a set of samples containing up to 7 at.\% Se (corresponding to a Tauc gap increase of 0.09 $\mathrm{eV})$ shows little change in the SAXS relative to a-Si:H and no evidence of Se clustering.

\section{4) SAXS interpretation and methodology:}

(a) An absolute calibration of the integrated SAXS signal for two-phase systems has been made based on theory and experiment. Experiments were made with four model two-phase systems: $\mathrm{AlAg}$ and $\mathrm{CuBe}$ alloys, $\mathrm{Sb}_{2} \mathrm{O}_{3}$ particles, and $\mathrm{CdTe}$ quantum dots. Theory and experiment agree within 15\%. The expected SAXS signal due to a given volume fraction of voids can be predicted on the basis of a two-phase microstructure consisting of voids of zero density in a hydrogenated amorphous matrix. A void fraction as low as $0.1 \%$ can be detected for films of $1 \mu \mathrm{m}$ thickness on a highpurity Al-foil substrate. The calibration work has also allowed our SAXS intensities to be converted to standard units (electron units) that now allows comparison to other results and to theoretical predictions, typically made in terms of these units.

(b) Identification of several scattering mechanisms that can contribute to the: SAXS, in addition to the standard electron density fluctuations such as microvoids, has been made and substantiated by theory. These include Laue monotonic scattering due to alloy diffuse scattering, thermal diffuse scattering due to atomic vibrations, static disorder diffuse scattering due to the amorphous structure, and incoherent Compton scattering. The intensity due to all of these mechanisms can be calculated in electron units and compared to experimental data. The most important of these is the alloy scattering effect and new information on the atomic-scale microstructure can be obtained via this effect. It is crucial to correct for these diffuse scattering mechanisms, all angle-independent or nearly so, in analyzing the SAXS data for microvoid contents, particularly for the weak-scattering, higher-quality materials.

(c) The contributions of $\mathrm{H}$ alloying and microvoids to the density deficits, as determined by flotation density measurements, can be separated on the basis of an atomic volume for $\mathrm{H}$ that is $40 \%$ that of $\mathrm{Si}$.

(d) Flotation densities of $\mathrm{a}_{-} \mathrm{Si}_{1-\mathrm{x}} \mathrm{Ge}_{\mathrm{x}}: \mathrm{H}$ alloys for $\mathrm{x}$ up to 0.57 show a systematically increasing density deficit (reaching 6\%) compared to crystalline densities for samples prepared in 5 different PECVD systems. Coexistence of Ge-rich or Si-rich regions in 
these films cannot yet be ruled out but the evidence presented here strongly supports the void (or low density H-rich domain) interpretation. There are differences in the degree of oriented-type microstructure for a similar $\mathrm{x}$ in films from different systems.

(e) Modeling of the sample tilting effects on the SAXS intensities due to oriented scattering centers is possible on the basis of a distribution of ellipsoidal voids. Values of the major/minor axis ratio can be estimated for the tilt data.

(f) Carefully designed experiments have established that interdiffusion is negligible between the aluminum foil substrate (used to prepare the films for SAXS) and the aSi:H provided that substrate temperatures are no higher than $400^{\circ} \mathrm{C}$. Temperatures below $350^{\circ} \mathrm{C}$ should be used for films containing Ge.

(g) A high sensitivity of SAXS to microcrystallinity in a-Si:H based films has been established with $\mu \mathrm{c}-\mathrm{Si}$ films and with a-Si:H films annealed above $400^{\circ} \mathrm{C}$ where microcrystalline regions develop. Integrated SAXS signals a factor more than 100 larger than device-quality a-Si:H are observed. 
1. EXECUTIVE SUMMARY

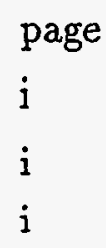

i

1.2 Conclusions

LIST OF FIGURES

vii

LIST OF TABLES

viii

2. INTRODUCTION 1

3. EXPERIMENTAL METHODS 2

4. RESULTS AND DISCUSSION 4

4.1 SAXS from a-Si:H 4

4.2 SAXS from a-SiGe:H $\quad 9$

4.3 SAXS from $\mathrm{a}-\mathrm{SiC}: \mathrm{H} \quad 13$

4.4 SAXS from related materials $\quad 16$

4.5 SAXS interpretation and methodology 23

5. ACKNOWLEDGEMENTS 29

6. REFERENCES 29

APPENDIX: List of Publication from this Research 31 
Fig 1. Comparison of SAXS data from a-SiGe:H alloys and a-Si:H

Fig 2. a)Ixh plots for a set of a-Si:H films prepared by $70 \mathrm{MHz}$ PECVD with Ar dilution; b) tilting data for two of the samples 3

Fig. 3. Correlation of integrated SAXS intensity and solar cell degradation 4

Fig. 4. SAXS data from several of the samples listed in Table 1

Fig. 5. SAXS at low $\mathrm{h}$ for a thick $(10 \mu \mathrm{m})$ versus a thin $(1 \mu \mathrm{m})$ a-Si:H film 8

Fig. 6. Correlation of SAXS and opto-electronic properties of a-SiGe:H alloy films prepared at Stuttgart Univ. (from ref. 23, appendix G). Also shown are the bandgaps and bonded $\mathrm{H}$ contents versus $\mathrm{Ge}$ content

Fig. 7. Comparison of integrated SAXS intensities from a-SiGe:H alloys prepared by PECVD by several groups 10

Fig. 8. Flotation densities of a-Si ${ }_{1-x} G_{x}: H$ compared to crystalline $\mathrm{Si}_{1-x} G_{x}$ alloys 11

Fig. 9. SAXS scans from RMS and PECVD a-SiC:H alloys 13

Fig. 10. Comparison of integrated SAXS intensities from a-SiC:H alloys prepared by two methods (RMS and PECVD)

Fig. 11. SAXS from sputter-deposited a-Ge:H prepared at UKL. Data from the Harvard film prepared with the $1.2 \mathrm{~cm}$ electrode spacing is shown for comparison

Fig. 12. Effect of $\mathrm{B}$ doping on the $\mathrm{SAXS}$ of a-Si:H and a-SiC:H films

Fig. 13. (a) SAXS intensity from $\mu \mathrm{c}-\mathrm{Si}: \mathrm{H}$ in the as-received state and after storage in air for increasing times; (b) Ixh plots showing the clear decrease in $\mathrm{Q}$ (area under curves) with time

Fig. 14. Integrated SAXS intensities and Si-bonded H contents (from IR) versus annealing temperature and time

Fig. 15. Distributions of void sizes in samples 1 and 4 before and at the conclusion of the annealing

Fig. 16. Comparison of theoretical and experimental SAXS Q's for two-phase calibration samples

Fig. 17. Matrix densities of a-Si:H films from flotation densities, corrected for small void fractions obtained from SAXS

Fig. 18. Theoretical Laue monotonic diffuse scattering contributions for random a-SiGe:H and a-SiC:H alloys with various $\mathrm{H}$ contents 27

Fig. 19. Diffuse scattering intensities from a-Si $\mathrm{Si}_{1-\mathrm{x}} \mathrm{Ge}_{x}: \mathrm{H}$ alloys 28

Fig. 20. Diffuse scattering intensities from a-Si $i_{1-x} \mathrm{C}_{x}: H$ alloys prepared by $\mathrm{RMS} 28$ 
Table 1. Summary of SAXS results and opto-electronic properties from highest quality a-Si:H from each group

Table 2. Preparation conditions, opto-electronic properties and SAXS results from Ge-rich a-SiGe:H alloys prepared at Harvard University

Table 3. Comparison of properties of a-SiC:H prepared by RMS vs PECVD

Table 4. Opto-electronic and SAXS results from Harvard a-Ge:H films

Table 5. Opto-electronic and SAXS results from U. Kaiserslautern a-Ge:H films

Table 6. SAXS, flotation densities and other results for B-doped a-Si:H and a-SiC:H films from Utrecht Univ

Table 7. SAXS and flotation density results from $\mu \mathrm{c}-\mathrm{Si}: \mathrm{H}$ films from Univ. of Illinois

Table 8. SAXS and other results from a-SiSe:H films from Texas A\&M Univ. 


\section{INTRODUCTION}

The term "microstructure" is a rather general one in materials science used to describe structural features that range in size depending on the structural probe. This term is most often associated with structural features observed directly with optical and electron microscopes where images with resolution from micrometers to nanometers are obtained. A recent, relevant example is the TEM observation of hydrogen-induced platelets in crystalline silicon which are only about 1 atomic layer thick but many nanometers in diameter ${ }^{1,2}$. Unfortunately, amorphous materials, such as the a-Si:Hbased solar cell films of interest here, yield relatively poor contrast with these conventional techniques unless they are extremely inhomogeneous and therefore typically of poor opto-electronic quality. Device-quality a-Si:H and a-SiGe:H appear homogeneous by $\mathrm{TEM}^{3,4}$. Spectroscopic methods such as electron spin resonance, infrared spectroscopy (IR), nuclear magnetic resonance (NMR), Raman, and positronannihilation are less direct microstructural probes but they are able to provide atomicscale structural information that often improves our understanding of the connection between structure and opto-electronic behavior. In some cases such as $\operatorname{IR}^{5}, \mathrm{NMR}^{6}$, and positron-annihilation ${ }^{7}$, larger-scale features such as microvoids or $\mathrm{H}$ clusters can be inferred. Non-random alloying effects that may be associated with either segregation or ordering can be deduced from Raman spectroscopy based on counting the type and fractions of the nearest-neighbor bonds ${ }^{8}$. Simple mass-density measurements using film flotation methods ${ }^{9,10}$ provide rather direct support for inhomogeneous, low-density material but yield no specific information on its microstructural nature.

During the last few years we have been applying a direct structural technique based on the diffraction of $\mathrm{x}$-rays to determine quantitatively some aspects of the microstructure of a-Si:H and the related alloys, a-SiGe:H and a-SiC:H. This somewhat uncommon technique, small-angle $\mathrm{x}$-ray scattering (SAXS), has proven to be a powerful and valuable probe. Our general objectives were to provide new details of the microstructure for the size scale from about 1 to $30 \mathrm{~nm}$ in high-quality a-Si:H and related alloys prepared by current state-of-the-art deposition methods as well as by new and emerging deposition technologies and thereby to help determine the role of microvoids and other density fluctuations in controlling the opto-electronic properties.

Results which support the conclusions listed in the Executive Summary for a-Si:H, a-SiGe:H and a-SiC:H are described in detail. In addition, a summary discussion is presented of the very different microstuctures existing in current state-of the art a-Si:H, a-SiGe:H, and a-SiC:H. 


\section{EXPERIMENTAL METHODS}

$\mathrm{X}$-ray intensity scattered at an angle $2 \theta$ relative to the incident beam passing through a sample is obtained with a highly collimated beam formed by a Kratky block collimation system ${ }^{11}$. The angle $2 \theta$ is usually converted into the magnitude of the momentum transfer during scattering, $\mathrm{h}=(4 \pi / \lambda) \sin \theta \simeq(2 \pi / \lambda) 2 \theta$, and the $\mathrm{x}$-ray intensity is collected in units of photons/s in a step-scan mode for a prescribed set of h's and times at each h. A sample consists of a film deposited onto a thin Al-foil substrate that can be folded to produce multiple layers and enhanced signals. A few films have been co-deposited onto thin c-Si wafers for comparison. The measured $\mathrm{x}$-ray intensity is corrected for substrate scattering and absorption effects, and normalized for variations in film thickness and incident intensity ${ }^{12}$ to yield what we call the normalized SAXS intensity, $I(h)$. Experimental data can be displayed as $\ln I(h)$ versus $h$ as shown in Fig. 1 for several a-SiGe:H alloys together with a set of data from a c-Si wafer for reference. Note in this figure that each set of data approaches an apparent constant level at high $\mathrm{h}$ and that this level depends on the Ge content. We now understand this behavior as due to diffuse scattering from at least two mechanisms (Laue monotonic scattering ${ }^{13}$ and disorder scattering). The data must be corrected for this effect by subtraction of the constant level of scattering in order to further analyze the remaining SAXS due to true microstructure effects. Further discussion of this effect and results from our consideration of possible substrate/film interdiffusion effects are discussed below in the "SAXS interpretation and methodology" section.

After correction for the diffuse scattering effect, a useful method of displaying data is to plot the product $\mathrm{hI}(\mathrm{h})$ versus $\mathrm{h}$ as shown in Fig. 2a for a set of a-Si:H films, since, under the assumption of a two-phase, randomly-oriented microstructure, the area under such a curve is directly proportional to the volume fraction of the minor phase ${ }^{14}$. This area, $\int \mathrm{I}(\mathrm{h}) \mathrm{hdh}=\mathrm{Q}$, represents the reduction of a set of SAXS data to a single number that can be used to quantitatively compare the microstructures of various samples. If an oriented microstructure is present then the SAXS and the resulting Q may be strongly affected and the direct proportionality with volume fraction is no longer valid. However, this case can be readily detected by tilting the sample relative to the $\mathrm{x}$-ray beam and monitoring the changes in $\mathrm{I}(\mathrm{h})$ and $\mathrm{Q}$. We have found it convenient to simply compare the $Q$ obtained at $0^{\circ}$ tilt angle compared to that at $45^{\circ}$ in the form of the ratio $\mathrm{Q}\left(0^{\circ}\right) / \mathrm{Q}\left(45^{\circ}\right)$. Figure $2 \mathrm{~b}$ shows an example of such tilting data for two samples of a$\mathrm{Si}: \mathrm{H}$. A ratio of unity demonstrates no oriented microstructure, while values greater than unity suggest elongated scattering centers with their long axes preferentially 
parallel to the growth direction similar to columnar-type microstructure. A ratio below unity would be consistent with plate-like scattering centers preferentially oriented with their large axes in the film plane.

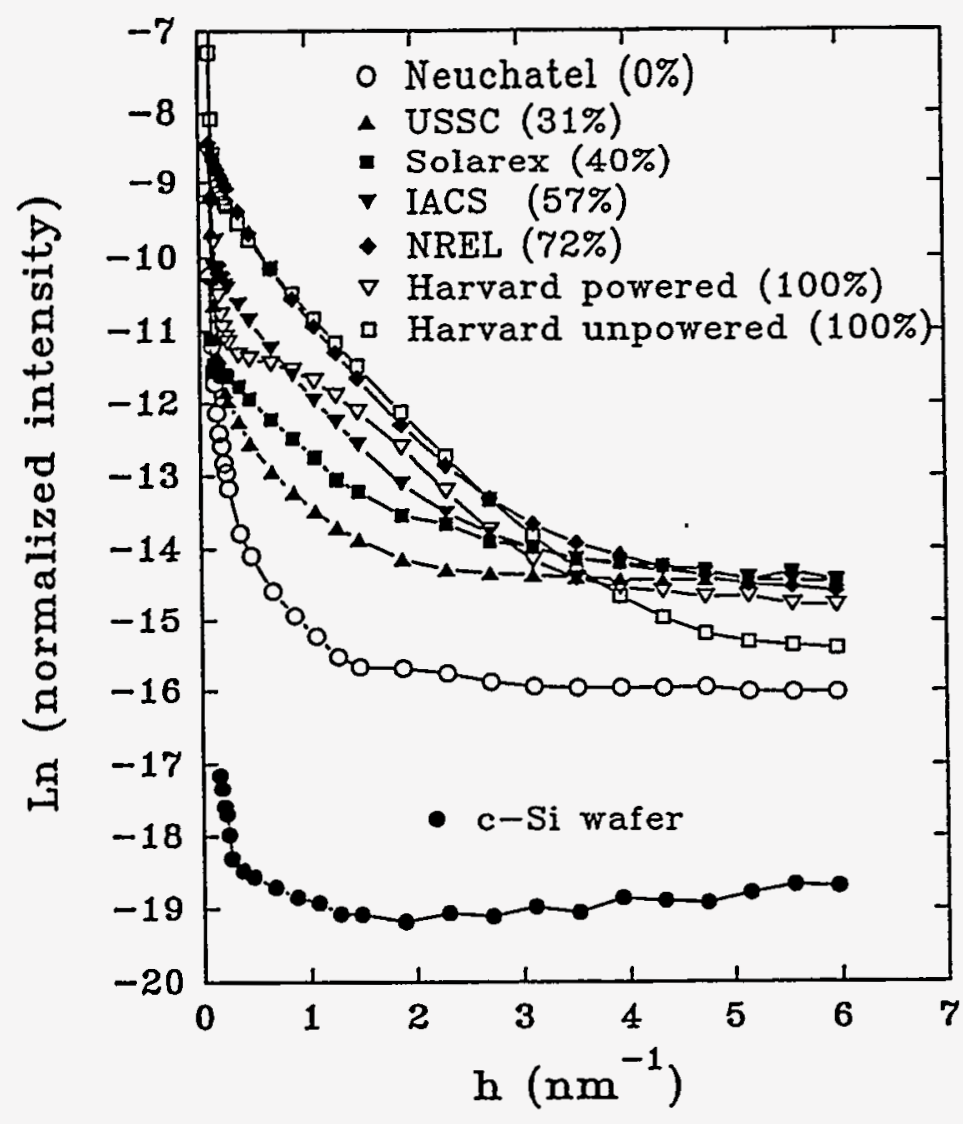

Fig. 1. Typical SAXS data for a-SiGe:H alloys (Ge at.\% in parentheses). Also shown are reference data from a c-Si wafer and data from a high-quality a-Si:H film.

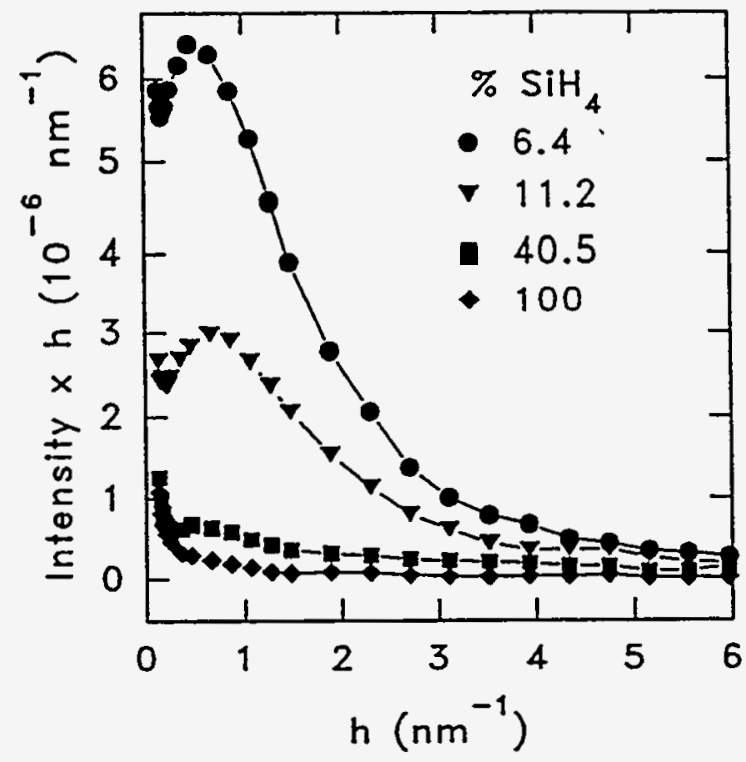

Fig. 2a. Ixh plots for a set of a-Si:H films prepared by $70 \mathrm{MHz}$ PECVD under Ar dilution

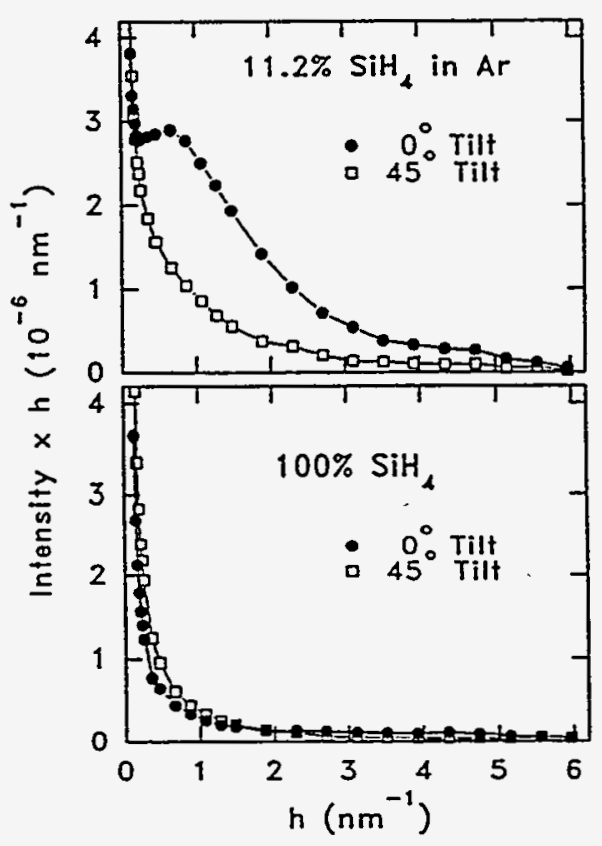

Fig. 2b. Tilting data for two of the samples of Fig. 2a. 


\section{RESULTS AND DISCUSSION}

\subsection{SAXS from a-Si:H}

We have made SAXS and flotation density measurements of numerous a-Si:H thin films prepared by if glow-discharge (PECVD), hotwire filament (HW), remote hydrogen plasma (RHP), reactive dc magnetron sputtering (RMS), and electron cyclotron resonance (ECR). Several of these samples can be characterized as "device quality" on the basis of their photoresponse and other opto-electronic properties. Deposition variables that were systematically varied included plasma power (primarily to change deposition rate), use of diluting gases $\left(\mathrm{H}_{2}, \mathrm{Ar}, \mathrm{He}\right.$, and $\mathrm{Xe}$ ), and substrate temperature. Suppliers of a-Si:H films produced by the various deposition methods included: PECVD - NREL, USSC, APS, Solarex, Ecole Polytechnique (Paris), Utrecht University, Stuttgart University, and the Indian Association for the Cultivation of Science (IACS); high-frequency PECVD - Univ. Neuchatel; HW-NREL; RHP-Xerox; RMS - University of Illinois; and ECR - JPL and Iowa State University.

A correlation of SAXS-determined microstructure and solar cell behavior has been obtained and reported ${ }^{15}$. A series of SAXS samples and solar cells were prepared by USSC with different deposition rates used for growth of the i-layer. This was done by adjusting the If power of the glow-discharge plasma. The increased microstructure in the form of microvoids about $1 \mathrm{~nm}$ in diameter, indicated by the values of $Q$, correlated with degraded solar cell efficiencies as summarized in Fig. 3 for the two extremes in deposition rate. Note that the solar cells with i-layers having the increased microvoid contents degraded more rapidly under light soaking for 600 hours. The increased microstructure was shown not to be associated with an oriented or columnar-like microstructure ${ }^{15}$.

Fig. 3. Correlation of SAXS with initial and degraded solar cell efficiencies

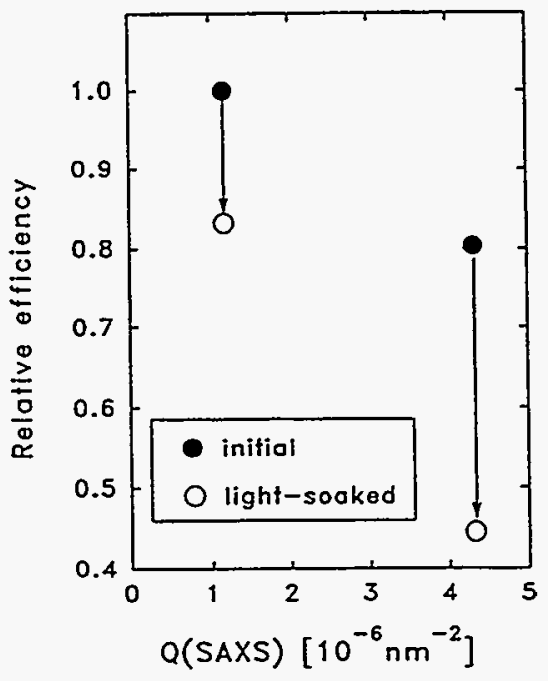


During the first year of this project, five device quality a-Si:H samples were measured in an annealed state $\left(170^{\circ} \mathrm{C}\right.$ for $\left.20 \mathrm{~h}\right)$ and in an accelerated light-soaked state $(20$ suns for $20 \mathrm{~h}$ ). For each of the five films, the SAXS data taken in the two states were the same within experimental uncertainty. To improve the accuracy, one film was first measured in the light-soaked state and then left mounted in the SAXS sample holder for external annealing $\left(170^{\circ} \mathrm{C}\right.$ for $\left.44 \mathrm{~h}\right)$. It was then reinserted in the SAXS system in the identical position and remeasured. The two sets of data are practically identical ${ }^{16}$. Based on these results we conclude that there is no change in the SAXSdetected microstructure due to the Staebler-Wronski effect. This result is not unexpected since (i) the structural changes which may accompany light soaking/annealing are small in magnitude and generally thought to be confined to an atomic scale associated with breaking/healing of weak $\mathrm{Si}-\mathrm{Si}$ or $\mathrm{Si}-\mathrm{H}$ bonds such that defect densities of about $10^{17} \mathrm{~cm}^{-3}$ are involved; (ii) the SAXS method is insensitive to hydrogen due to weak $x$-ray scattering from its one electron per atom. However, the microvoids or H-rich domains, as detected by SAXS, are at least this dense and therefore may play a direct role as the source of $\mathrm{H}$ or the location of the weak bonds.

Several of the other a-Si:H samples produced by the various methods and under certain conditions showed a significant amount of SAXS-determined microstructure that correlated systematically with deposition variables and degraded opto-electronic behavior:

(a) The use of a larger amount of Ar dilution during $70 \mathrm{MHz}$ PECVD deposition caused clear increases in $\mathrm{Q}$ and this was accompanied by a lowering of the photoconductivity, a broadening of the Urbach edge and an increase in sub-bangap absorption ${ }^{17}$. A clear transition to oriented, columnar-like microstructure was induced by the Ar dilution.

(b) He dilution of a standard $13.56 \mathrm{MHz}$ plasma, coupled with an increase in substrate temperature from 250 to $320^{\circ} \mathrm{C}$ allowed an increase in deposition rate to $1.2 \mathrm{~nm} / \mathrm{s}$ with $Q$ values and opto-electronic properties typical of device-quality material ${ }^{17}$. The scattering centers produced in the He dilution study were significantly smaller than those of the Ar dilution study and there was less tendency for an oriented microstructure.

(c) The deposition of a-Si:H at high rates by the cathode heating technique ${ }^{18}$ has yielded a correlation SAXS-determined microstructure and powder formation in the plasma due to gas-phase polymerization ${ }^{19}$. Enhanced void fractions and poorer initial and light-soaked photoresponse were observed for the films grown under dusty plasma conditions.

For other a-Si:H deposition methods $\left[\right.$ Hotwire ${ }^{20}, \mathrm{ECR}^{21}$ and $\mathrm{RMS}^{22}$ ] a significant 
amount of SAXS-detected microstructure was present and yet photo/dark conductivity ratios typical of device-quality material were obtained. However, none of these materials were incorporated as i-layers into solar cells to evaluate their device performance. Films from APS and Solarex that represent their current state-of-the-art a-Si:H used as the ilayer in their best solar cells have been studied and the SAXS Q-values are among the lowest yet observed. The remote hydrogen plasma (RHP) method developed at Xerox also yields quite low SAXS.

For convienient comparison of the SAXS from a-Si:H deposited by various groups and by the various methods, data are listed in Table 1 and several complete sets of SAXS data are plotted in Fig. 4, where the variability in angular dependence and intensity is due to different size distributions and volume fractions of scattering centers in the various a-Si:H films, respectively. The samples from each group that yield the lowest SAXS Q-values are included along with the known deposition conditions and known opto-electronic properties. Assuming that only voids are responsible for the listed Q's, the maximum possible void volume fractions can be calculated on the basis of the approximate expression $V_{\mathrm{f}}($ in $\%) \simeq \mathrm{Q} / 4 \times 10^{-6} \mathrm{~nm}^{-2}$ (this is not exact because it depends on the $\mathrm{H}$ content bonded in the matrix). Flotation densities and total bonded $\mathrm{H}$ contents (via IR) are listed as well.

Examination of the data in Table 1 reveals that several samples have maximum void fractions that are less than $0.1 \%$ and that are approaching our detection limit with the SAXS system of about $0.03 \%$. In fact, these best quality samples may contain less voids than indicated since the $Q$ obtained from these samples is predominantly due to scattering at low h (see Fig. 4) which corresponds to some larger-scale microstructural features that are not likely to be voids. To explore more carefully this smaller-angle scattering, some experiments were made on two of the high-quality films using a narrower entrance slit of $42 \mu \mathrm{m}$ vs our standard slit of $130 \mu \mathrm{m}$. The two samples examined had different thicknesses of about 1 and $10 \mu \mathrm{m}$ so that the possibility of surface roughness could be tested as one origin of the small-h signals. However, as shown in Fig. 5 the normalized data are quite similar in magnitude, suggesting a bulk mechanism. (However, these two films were grown by different groups and a more careful study of a possible surface roughness effect is needed). The log-log plot of Fig. 5 yields a slope near that of the Porod law of -3 showing that we are probably seeing only the tails of the scattering curves caused by structural features that must be larger than about $30 \mathrm{~nm}$ in size. One can estimate whether $\mathrm{H}$ concentration fluctuations of on this size scale could be the source of the SAXS. For example, if one considers the a-Si:H 


\begin{tabular}{|c|c|c|c|c|c|c|c|c|}
\hline Group & $\begin{array}{l}\text { Depnsillion } \\
\text { method }\end{array}$ & Preparation details & $\begin{array}{c}Q_{0} \\
\left(10^{-6} \mathrm{~nm}^{-2}\right) \\
\text { (llickness) }\end{array}$ & $\mathbf{Q}_{0} / \mathbf{Q}_{15}$ & $\begin{array}{c}\mathrm{h} \\
\left(\times 10^{\cdot 7}\right)\end{array}$ & $\begin{array}{l}\mathrm{C}_{\mathrm{H}} \\
(\mathrm{al} \%)\end{array}$ & $\begin{array}{l}\rho_{\text {กol }} \\
\left(\mathrm{g} / \mathrm{cm}^{3}\right)\end{array}$ & Opto-electronic properties \\
\hline $\begin{array}{l}\text { APS } \\
\text { \#B751 }\end{array}$ & Plic(VI) & $\begin{array}{l}2(0) 1)^{1} \mathrm{C} ; \text { I sccm; H-dilu } \\
0.15 \mathrm{mbar} ; 10 \mathrm{~mW}\end{array}$ & $\begin{array}{c}0.3 \\
(3.0 \mu \mathrm{min})\end{array}$ & 1.0 & 0.8 & -7 & 2.24 & $\begin{array}{l}\text { cell efficiency } 8 \% \\
\text { (stabilized) }\end{array}$ \\
\hline $\begin{array}{l}\text { Ecole poly } \\
\forall 304144\end{array}$ & PIICVI) & $\begin{array}{l}60 \% \text { lle dilu; } \\
350^{\circ} \mathrm{C} ; 1.12 \mathrm{~nm} / \mathrm{s}\end{array}$ & $\begin{array}{c}0.3 \\
(4.7 \mu m)\end{array}$ & 1.0 & 0.9 & 9.2 & 2.2 .3 & $\begin{array}{l}N \mathrm{~d}(\mathrm{PDS}) ; \sim \times 10^{16} \mathrm{~cm}^{-3} ; \mathrm{R}=0.05 \\
\mathrm{E}_{0}=49 \mathrm{meV} ; \sigma_{\text {pholo }}=6.6 \times 10^{-7}(\mathrm{olum}+\mathrm{cm})^{-1}\end{array}$ \\
\hline $\begin{array}{l}\text { IACS } \\
\text { HCIl.33 }\end{array}$ & PI:CVD & $\begin{array}{l}180^{\prime \prime C ; 20 s c m ~} \\
0.32 \mathrm{nun} / \mathrm{s} ; \text { II-dilu }\end{array}$ & $\begin{array}{c}1.4 \\
(6.4 \mu \mathrm{m})\end{array}$ & 1.7 & 1.9 & 15.5 & 2.18 & $\mathrm{R}=0.33$ \\
\hline $\begin{array}{l}\text { Illinnis } \\
\text { H1780T }\end{array}$ & RMS & $\begin{array}{l}0.16 \mathrm{mTorr} P_{112} \\
230^{\circ} \mathrm{C}\end{array}$ & $\begin{array}{c}2.1 \\
(2.4 \mu \mathrm{mI})\end{array}$ & 1.5 & 0.5 & 9.2 & 2.26 & $\begin{array}{l}\mathrm{R}=0.05 ; \mathrm{Eg}=1.71 \mathrm{eV} ; \sigma_{\text {photal }} \sigma_{\mathrm{duk}}=2.0 \times 10^{3} \\
\mathrm{E}_{0}=51 \mathrm{meV} ; \mathrm{Nu}(\mathrm{PDS}) ;-1.6 \times 10^{16} \mathrm{~cm}^{-3}\end{array}$ \\
\hline $\begin{array}{l}\text { Iorva State } \\
\forall 1 / 38 G\end{array}$ & $\overline{E C R}$ & $\cdots$ & $(0.9 \mu \mathrm{mm})$ & $\cdots$ & $\cdots$ & $\cdots$ & $\cdots$ & $\cdots$ \\
\hline $\begin{array}{l}\text { JPL } \\
H 20115 B\end{array}$ & I:CR & $\begin{array}{l}350^{\circ} \mathrm{C} ; 20 \mathrm{sccm} ; 300 \mathrm{~W} \\
\mathrm{Xe} 15 \mathrm{sccni} ; 1.0 \mathrm{ni} \text { Tor }\end{array}$ & $\begin{array}{c}1.8 \\
(1.2 \mu \mathrm{m})\end{array}$ & 1.0 & 0.5 & $\cdots$ & 2.2 .3 & $\sigma_{\text {phnto } /} \sigma_{\mathrm{dak}}=2.8 \times 10^{6}$ \\
\hline $\begin{array}{l}\text { Neuchatel } \\
\$ 17029.3\end{array}$ & $\begin{array}{l}\text { VIll:- } \\
\text { PECVD }\end{array}$ & $\begin{array}{l}70 \mathrm{MH}, ; ; 0.22 \mathrm{mbar} \\
9 \mathrm{~W} ; 300^{\circ} \mathrm{C} ; 40 \mathrm{sccm}\end{array}$ & $\begin{array}{c}0.1 \\
(3.2 \mu \mathrm{mI})\end{array}$ & 0.9 & 0.5 & 9.0 & 2.24 & $\begin{array}{l}\mathrm{R}=0.1 ; \mathrm{Eg}=1.69 \mathrm{cV} \\
\sigma_{\text {pholol }} \sigma_{\text {dark }}=-2.0 \times 10^{5}\end{array}$ \\
\hline $\begin{array}{l}\text { NREL } \\
H 128\end{array}$ & Inot wire & $\begin{array}{l}300^{\circ} \mathrm{C} ; 20 \mathrm{sccm} ; \\
7 \mathrm{~m} \text { lorr; } 1 \mathrm{~nm} / \mathrm{s}\end{array}$ & $\begin{array}{c}3.0 \\
(2.9 \mu 011)\end{array}$ & 1.7 & 1.3 & 12.0 & 2.18 & $\begin{array}{l}\mathrm{E}_{\mathrm{g}}=1.71 \mathrm{cV} ; \eta \mu \tau=1.2 \times 10^{-8}\left(\mathrm{~cm}^{2} \mathrm{~V}^{-1}\right) \\
\mathrm{E}_{0}=51 \mathrm{nicV} ; \sigma_{\text {pholo }} \sigma_{\text {dark }}=3 .\left(1 \times 10^{5}\right.\end{array}$ \\
\hline $\begin{array}{l}\text { NREL } \\
\sharp \wedge 9 / 12 / 90\end{array}$ & PIICVD & $300^{\circ} \mathrm{C}$ & $\begin{array}{c}0.6 \\
(1.7 \mu n \prime \prime)\end{array}$ & 0.9 & 0.5 & 7.5 & $\therefore$ & $\begin{array}{l}\mathrm{Eg}_{\mathrm{g}}=1.65 \mathrm{eV} ; \eta \mu \tau=2.0 \times 10^{-6}\left(\mathrm{~cm}^{2} \mathrm{~V}^{-1}\right) \\
\mathrm{E}_{0}=49 \mathrm{mcV} ; \mathrm{Nd}(\mathrm{PDS}) ;-7 \times 10^{1.5} \mathrm{~cm}^{-3}\end{array}$ \\
\hline $\begin{array}{l}\text { Princetun } \\
\sharp \mathrm{M} 280\end{array}$ & PI:CVD & $\cdots$ & $\begin{array}{c}1.1 \\
(1.0 \mu m)\end{array}$ & 1.2 & 1.9 & $\cdots$ & $\cdots$ & $\begin{array}{l}\mathrm{E}_{\mathrm{g}}=1.75 \mathrm{cV} ; \sigma_{\text {photh }} \sigma_{\mathrm{dak}}=3.8 \times 10^{5} \\
\mathrm{E}_{0}=52 \mathrm{mcV} ; \mathrm{Nd}(\mathrm{CPM}):-9 \times 10^{15} \mathrm{~cm}^{-3}\end{array}$ \\
\hline $\begin{array}{l}\text { Stuttgart } \\
\# .205251\end{array}$ & PI:CVI) & $\begin{array}{l}2010^{n} \mathrm{C} ; 30 \mathrm{sccm} ; 11 \text {-dilu } \\
0.34 \mathrm{mbar} ; 50 \mathrm{~mW} / \mathrm{cm}^{2}\end{array}$ & $(2.5 \mu \mathrm{m})$ & 1.0 & 0.5 & 7.7 & $\cdots$ & $\begin{array}{l}\mathrm{E}_{0}=56 \mathrm{mcV} ; \mathrm{Eg}_{\mathrm{g}}=1.72 \mathrm{cV}, \sigma_{\text {photh }} \sigma_{\text {Jark }}=3.6 \times 10^{4} \\
\mathrm{Nu}(\mathrm{PDS}) ; \sim 2 \times 10^{16} \mathrm{~cm}^{-3}\end{array}$ \\
\hline $\begin{array}{l}\text { USSC } \\
\sharp 4810\end{array}$ & PI:(VI) & $0.14 \mathrm{~m} 11 / \mathrm{s} ; 3(0))^{\circ} \mathrm{C}$ & $\begin{array}{c}1.2 \\
(0.9 \mu n)\end{array}$ & 1.0 & 0.9 & 8.0 & 2.24 & $\begin{array}{l}R=0.08 ; \text { cell cfficiency: } 7.85 \% \text { (initial) } \\
\& 6.53 \% \text { (stabilized) }\end{array}$ \\
\hline $\begin{array}{l}\text { Utrecht } \\
\forall \wedge 422\end{array}$ & P|!(V) & $\begin{array}{l}200^{\circ} \mathrm{C} ; 30 \mathrm{sccm} \\
10 \mathrm{~W}: 0.12 \mathrm{mbar}\end{array}$ & $\begin{array}{c}1.1 \\
(1.3 \mu n n)\end{array}$ & 1.0 & 1.4 & 12.0 & 2.20 & $\mathrm{R}=0.13 ; \mathrm{Eg}=171 \mathrm{eV}$ \\
\hline $\begin{array}{l}\text { Xerox } \\
\forall 444\end{array}$ & RIIP & $\begin{array}{l}400^{\circ} \mathrm{C} ; 400 \mathrm{~W} ; \mathrm{H} \cdot \mathrm{dil} \text { ! } \\
\text { I0secm: } 0.5 \text { inlinm }\end{array}$ & $\begin{array}{c}0.4 \\
(2.3 \mu \mathrm{mI})\end{array}$ & 1.0 & 0.6 & $\sim 10$ & 2.21 & $\begin{array}{l}\mathrm{E}_{0}=5() \mathrm{meV} \\
\left.\mathrm{Nu}\left({ }^{\prime} \mid\right) \mathrm{S}\right):-3 \times 1()^{1 / 5} \mathrm{ctn}^{-1}\end{array}$ \\
\hline
\end{tabular}

$\mathrm{C}_{\mathrm{H}}$ : bonded $\mathrm{H}$ content (vin IR);

$\rho_{\text {not: }}$ film density via fotation method: $\mathrm{N}_{\mathrm{d}}$ : defect density:
$\mathbf{E}_{(0)}$ : Urbach cnergy:

$\sigma$ : conductivity:

$\mathbf{E}_{\mathrm{g}}$ : Tauc gap; $\eta \mu \tau:$ quantum efficiency, mobility, lifetime product

R: [(2080)/[I(2000)+I(2080)], where I is integrated IR intensity 


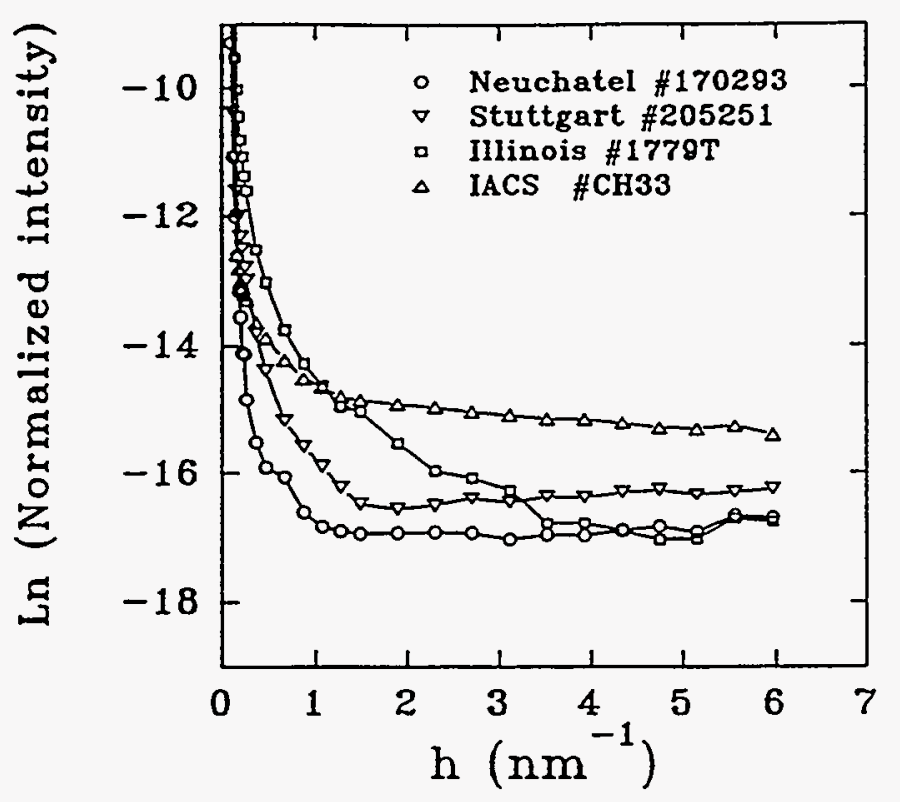

Fig. 4. SAXS scans from some of the samples listed in Table 1.

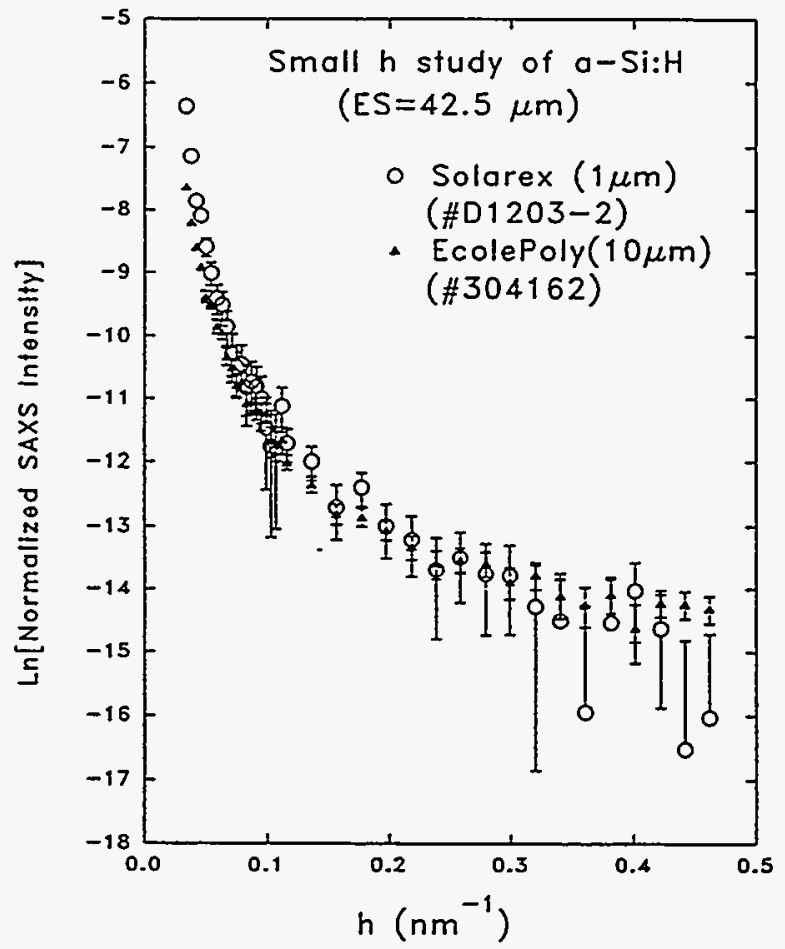

Fig. 5. SAXS at low $\mathrm{h}$ for thick $(10 \mu \mathrm{m})$ vs. thin $(1 \mu \mathrm{m})$ a-Si:H films.

matrix as a two-phase system with some fraction, $f$, of its volume with a 10 at. $\% \mathrm{H}$ content (bonded in the matrix) and the other fraction, 1-f, at $10+\delta$ at.\% $\mathrm{H}$, then one can calculate that the expected $Q \simeq 0.0065 \delta^{2} \mathrm{f}(1-\mathrm{f}) \times 10^{-6} \mathrm{~nm}^{-2}$ (i.e., in the same normalized intensity units of Table 1). Since the maximum possible value of $f(1-f)=0.25$ and most of the $Q$ will not be detected experimentally due to their large size, we can safely write $\mathrm{Q}(\max )=0.0016 \delta^{2} \times 10^{-6} \mathrm{~nm}^{-2}$. Thus, even $\delta=3 \%$ will cause a $Q$ that is about an order-ofmagnitude below the lowest values in Table 1 so that this type of mechanism does not appear feasible. Further work is needed to clarify the origin of this low-angle, weak, but perhaps significant SAXS. 


\subsection{SAXS from a-SiGe:H}

Several sets of a-SiGe:H alloys from various groups have been analyzed. These include PECVD films from NREL, Solarex, USSC, Stuttgart University, Harvard University, IACS, and Princeton University. The latter samples were prepared with $\mathrm{GeF}_{4}$ rather than $\mathrm{GeH}_{4}$. Some of the SAXS data from these samples as well as data from Harvard a-Ge:H films were compared in Fig. 1 together with a typical devicequality a-Si:H sample and our reference crystalline-Si data. An initial investigation of several a-SiGe:H alloy films ${ }^{23}$ has now been supplemented by more extensive and systematic studies as described below.

A systematic series of 10 samples from Stuttgart University with Ge contents from 0 to 37 at.\% provide strong evidence for a direct link between the SAXS-determined microstructure and opto-electronic degradation ${ }^{24}$. Above about 20 at.\% Ge a sharp transition in the microstructure occurs consistent with a change to columnar-like growth. As shown in Fig. 6, above this same composition the photo/dark conductivity ratio and the defect density determined by photothermal deflection spectroscopy (PDS) show significant decreases and increases, respectively.

A comparison of the Q's from the Stuttgart samples with those from alloys made by the other groups is shown in Fig. 7. There is apparently an ubiquitous problem in the microstructure of a-SiGe:H alloys with Ge content above 20-30 at.\%. These same high concentrations also lead to $Q\left(0^{\circ}\right) / Q\left(45^{\circ}\right)$ ratios in the range from 2 to 5 indicating strongly oriented microstructures ${ }^{21}$. Flotation densities from all a- $\mathrm{Si}_{1-x} \mathrm{Ge}_{x}: \mathrm{H}$ films with $\mathrm{x}$ below 0.6 (the density limit of our fluid) are shown in Fig. 8 in comparison with the density of crystalline alloys ${ }^{25}$. A quadratic fit to the data and the resulting difference from the crystalline alloys is shown in the lower plot of Fig. 8. Note that the density deficit reaches $6 \%$, consistent with an interpretation of voids or low density, H-rich regions as the source of the SAXS. The $\mathrm{H}$ content generally decreases with increasing $\mathrm{Ge}$, so the increased deficit cannot be attributed to $\mathrm{H}$ in the matrix. Japanese researchers have been suggesting that alloy segregation (Ge-clusters) is the origin of the $\mathrm{SAXS}$ in a-SiGe:H alloys ${ }^{26,27}$.

Additional evidence that such large-scale Ge clustering is not responsible for the SAXS comes from measurements of several a-Ge:H films prepared by PECVD at Harvard. The SAXS signals are quite similar to those from the SiGe alloys (Fig. 1) but, of course, no Ge clustering can be present in such material, except relative to the $\mathrm{H}$ and voids, which is our interpretation of the origin of the SAXS. Further details of SAXS studies of a-Ge:H films is presented later. 


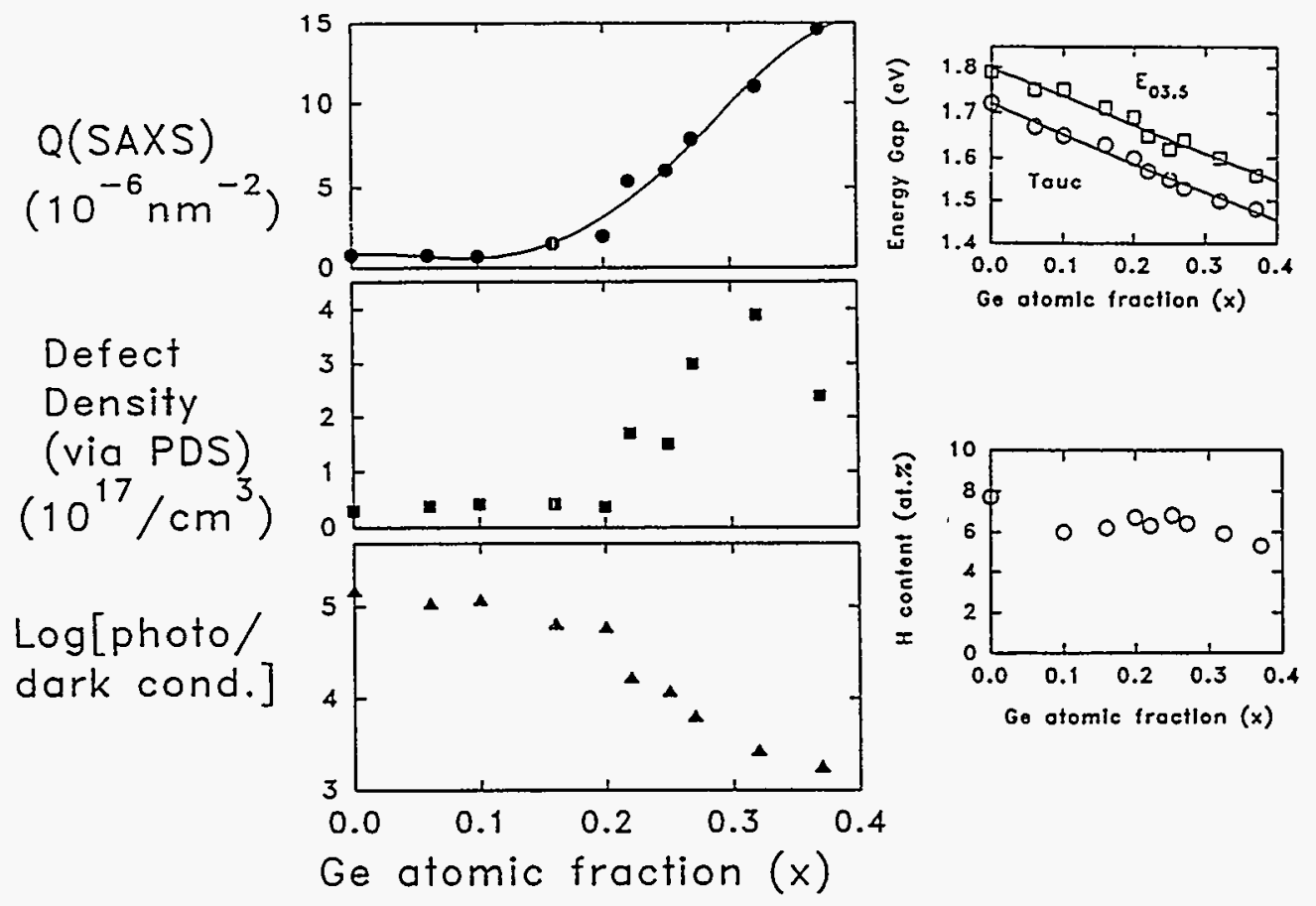

Fig. 6. Correlation of SAXS and opto-electronic properties of a-SiGe:H alloy films prepared at Stuttgart Univ. (from ref. 23). Also shown are the bandgaps and bonded $\mathrm{H}$ contents versus $\mathrm{Ge}$ content.

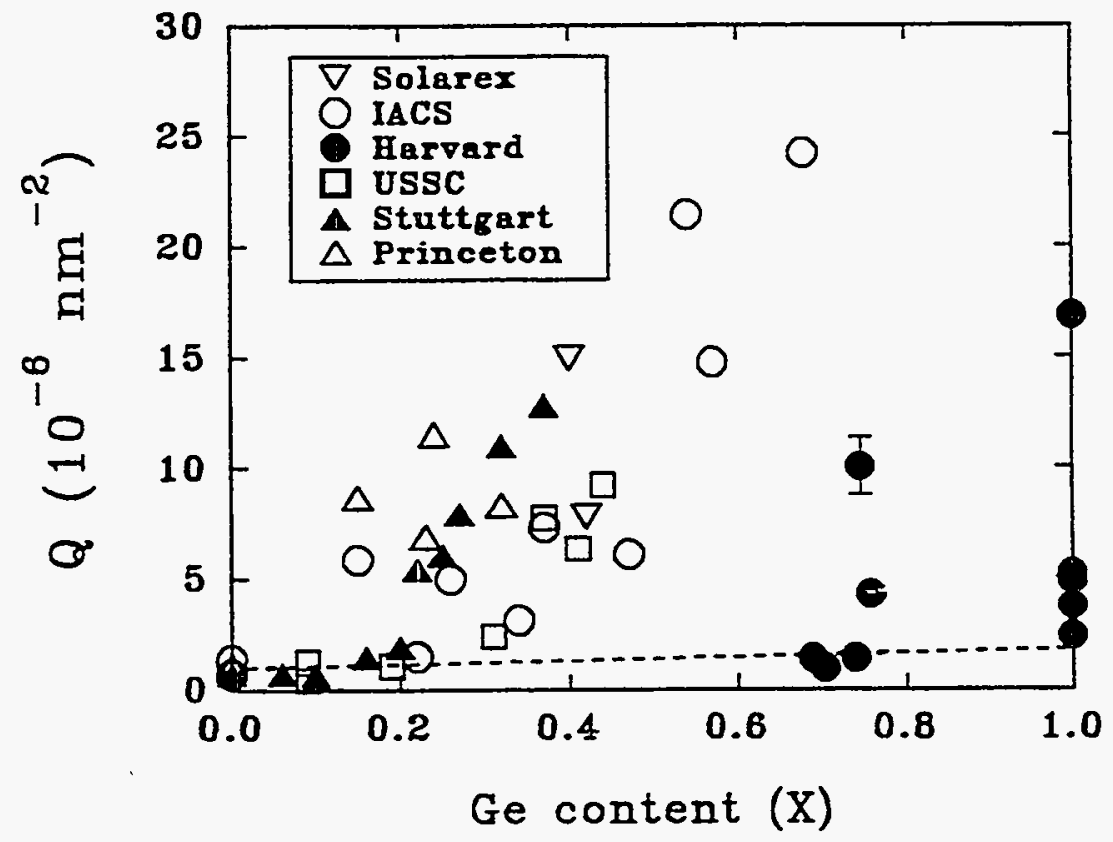

Fig. 7. Comparison of integrated SAXS intensities from a-SiGe:H alloys prepared by PECVD by several groups. 


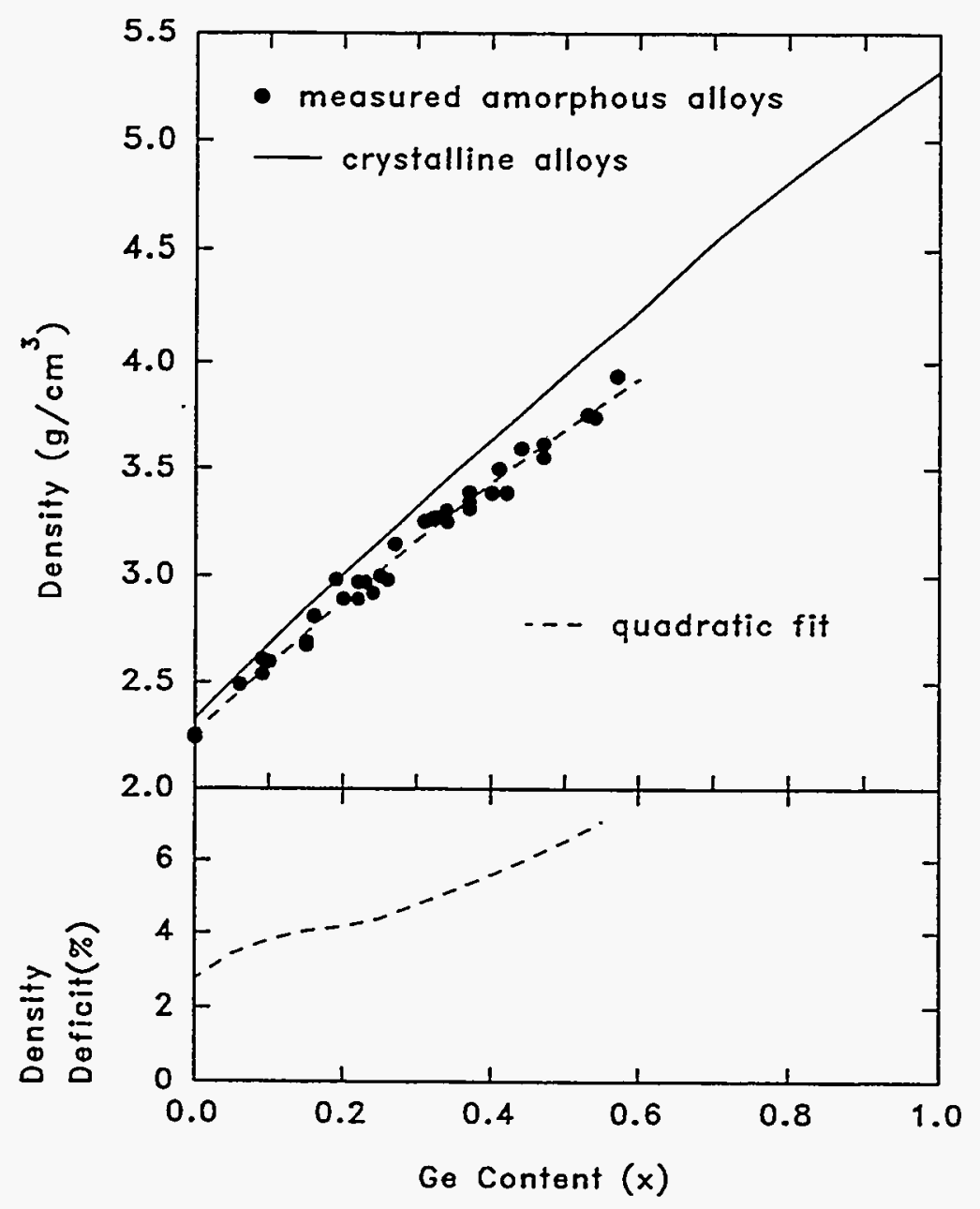

Fig. 8. Flotation densities of a-Si $i_{1-x} \mathrm{Ge}_{\mathrm{x}}: \mathrm{H}$ compared to crystalline $\mathrm{Si}_{1-\mathrm{x}} \mathrm{Ge}_{\mathrm{x}}$ alloys.

A USSC series of alloys (included in Fig. 4) shows a similar trend to that of the Stuttgart series in that oriented microstructure appears for the 31 and $41 \%$ Ge films, although the magnitudes of the increases in $Q$ are not as great, suggesting more homogeneous microstructure than the Stuttgart films for similar Ge content. Solar cells containing i-layers made under identical deposition conditions used for the SAXS samples show systematically reduced initial efficiencies with increasing Ge while the Q's do not increase significantly until the above $\mathrm{Ge}$ contents are reached. However, increased light-induced degradation was observed for these two higher Ge content solar cells. Details of this study have been reported ${ }^{28}$. Further research is needed to understand the role of SAXS-detected microstructure in film opto-electronic properties versus photovoltaic properties. The direction of carrier transport relative to the film plane may be important in cases where oriented microstructure is present ${ }^{28}$. 
The Princeton material, prepared with $\mathrm{GeF}_{4}$, suggests a significantly different size distribution of scattering centers and a reduced tendency for columnar-like microstructure. Thus, the source gas can have a strong effect on the microstructural character of the film.

Recent Ge-rich a-SiGe:H alloys prepared at Harvard by PECVD on the powered electrode (cathode) are of particular interest due to a sharp improvement in optoelectronic properties for such high Ge films and a corresponding sharp reduction in SAXS-detected microstructure. These results are included in Fig. 7 where one can see the low Q's for $x$ near 0.7, clearly much lower than most of the values from samples with $0.2<x<0.6$. Table 2 lists the deposition conditions, opto-electronic properties, and SAXS results for these new samples. Note that the values of $Q\left(0^{\circ}\right) / Q\left(45^{\circ}\right)$ are near unity so that the oriented type of microstructure has essentially been eliminated. Such results suggest that modified deposition conditions could also lead to elimination of the significant microstructural inhomogeniety remaining in the lower Ge-content material of interest for the low bandgap i-layer of a multijunction cell, $\mathrm{x} \simeq 0.4-0.5$.

Table 2. Preparation conditions, opto-electronic properties, and SAXS results from PECVD a-SiGe:H alloys prepared at Harvard University.

\begin{tabular}{|c|c|c|c|c|c|c|c|c|c|c|c|c|}
\hline $\begin{array}{l}\text { SAXS } \\
\text { sample }\end{array}$ & $\begin{array}{l}\text { Corre- } \\
\text { sponding } \\
\text { sample }\end{array}$ & $\begin{array}{l}\text { Deposition conditions } \\
\mathrm{H}_{2}: \mathrm{SiH}_{4}: \mathrm{GeH}_{4} / \mathrm{D}(\mathrm{cm})\end{array}$ & $\begin{array}{l}E_{04} \\
(\mathrm{eV})\end{array}$ & $\begin{array}{l}E_{03} \\
(e V)\end{array}$ & $\begin{array}{l}\mathrm{C}_{\mathrm{GeH}} \\
\text { (at.\%) }\end{array}$ & $\begin{array}{c}\mathrm{CSiH}_{\mathrm{SiH}} \\
\text { (at.\%) }\end{array}$ & $\begin{array}{l}\mathrm{C}_{\mathbf{H}, \text { tot }} \\
\text { (at.\%) }\end{array}$ & $\begin{array}{c}\text { GR } \\
\left(\dot{A} s^{-1}\right)\end{array}$ & $\begin{array}{c}\eta \mu \tau \\
\left(\mathrm{cm}^{2} s^{1}\right)\end{array}$ & $\begin{array}{l}E_{\text {act }} \\
(e V)\end{array}$ & $\begin{array}{l}L_{0} \\
(\dot{A})\end{array}$ & $\begin{array}{l}\text { stress } \\
\text { (kbar) }\end{array}$ \\
\hline 395 & 415 & $40: 1.0: 1.0 \quad / 1.0$ & 1.57 & 1.39 & 4.5 & 15.6 & 20.1 & 9.59 & $3.0 \mathrm{e}-8$ & 0.64 & 598 & -5.4 \\
\hline 401 & 398 & $40: 0.5: 1.0$ & 1.40 & 1.25 & 5.4 & 5.5 & 10.9 & 7.76 & $9.3 e-8$ & 0.59 & 494 & 4.9 \\
\hline 404 & 403 & $40: 0.3: 1.0$ & 1.36 & 1.21 & 5.7 & 6.5 & 12.2 & 6.79 & $1.6 \mathrm{e}-7$ & 0.58 & 552 & -6.2 \\
\hline 416 & NA & $40: 1.0: 1.0$ & & & & & & & & & & \\
\hline 418 & 417 & $60: 1.0: 1.0$ & 1.56 & 1.39 & 6.6 & 12.1 & 18.7 & 7.78 & $9.8 \mathrm{e}-8$ & 0.67 & 527 & -5.9 \\
\hline 420 & 419 & $80: 1.0: 1.0$ & 1.52 & 1.34 & 6.1 & 10.2 & 16.3 & 6.74 & $3.5 e-8$ & & 481 & -5.6 \\
\hline 422 & 421 & $20: 1.0: 1.0$ & 1.52 & 1.33 & 3.5 & 14.0 & 17.5 & 13.3 & $6.1 \mathrm{e}-8$ & 0.65 & 517 & -5.7 \\
\hline 423 & 415 & $40: 1.0: 1.0$ & 1.57 & 1.39 & 4.5 & 15.6 & 20.1 & 9.59 & $3.0 \mathrm{e}-8$ & 0.64 & 598 & -5.9 \\
\hline
\end{tabular}

- All other deposition conditions were the same: $225^{\circ} \mathrm{C}, 30$ Watts, 0.95 Torr, powered electrode.

\begin{tabular}{|l|c|c|c|c|c|}
\hline Sample & $\begin{array}{c}\mathbf{X}_{\mathrm{Ge}} \\
(\mathrm{at} \%)\end{array}$ & $\begin{array}{c}\mathrm{Q}_{0} \\
\left(10^{-6} \mathrm{~nm}^{-2}\right)\end{array}$ & $\mathbf{Q}_{\mathbf{0}} / \mathrm{Q}_{\mathbf{4 5}}$ & $\begin{array}{c}\mathbf{I}_{\mathbf{A}} \\
\left(10^{-7}\right)\end{array}$ & $\begin{array}{c}\text { Thickness } \\
(\mu \mathrm{m})\end{array}$ \\
\hline$\# 395$ & 72.0 & 2.8 & 0.7 & 3.9 & 0.7 \\
\hline$\# 401$ & 84.0 & 19 & 2.4 & 2.5 & 0.6 \\
\hline$\# 404$ & 86.0 & 13 & - & 3.3 & 3.0 \\
\hline$\# 416$ & 74.0 & 1.4 & 0.9 & 5.3 & 5.0 \\
\hline$\# 418$ & 75.8 & 4.3 & 1.0 & 5.7 & 3.6 \\
\hline$\# 420$ & 74.6 & 10 & 1.5 & 5.2 & 3.9 \\
\hline$\# 422$ & 68.9 & 1.4 & 0.9 & 4.6 & 3.6 \\
\hline$\# 423$ & 70.4 & 1.0 & -0.9 & 4.8 & 4.2 \\
\hline
\end{tabular}




\subsection{SAXS from a-SiC:H}

Figures 9 and 10 compare the SAXS intensity scans and microstructure quantity $Q$ for several samples of a-SiC:H films prepared by reactive dc magnetron sputtering ${ }^{22}$, RMS, at the Univ. of Illinois and by PECVD at Solarex. Although methane was the source of the $\mathrm{C}$ in both cases, there are significant differences in microstructure. All of the RMS films show a significant tilting effect such that $Q\left(0^{\circ}\right) / Q\left(45^{\circ}\right)$ is $1.3-1.6$ while the PECVD material yields ratios of 0.9-1.2 (only one was above 1.1). Thus, oriented microstructure exists in the RMS material while more random orientations exists in the PECVD films. Also, the $\mathrm{I}(\mathrm{h})$ data in Fig. 9 show quite different behavior with $\mathrm{h}$ for the two types of deposition, suggesting a quite narrow distribution of $1 \mathrm{~nm}$ diameter scattering centers in the PECVD material and a wider distribution of somewhat larger scattering centers in the RMS films. One may compare the Q's in Figs. 7 and 10 to see that $\mathrm{C}$ incorporation of less than 20 at.\% leads to much more microstructure, in contrast to Ge alloying.

The appearance of a shoulder-like pattern in the SAXS of the PECVD films (Fig. 9) indicates an interparticle interference effect. Generally, there are two criteria that need to be met for the occurrence of this effect ${ }^{11}$ : (i) a high density of scattering centers and (ii) a rather narrow size distribution. Earlier results from PECVD a-SiC:H alloys prepared at NREL ${ }^{12,29}$ also showed the shoulder-like feature in the SAXS and there it was proposed that the high density of $\mathrm{CH}_{3}$ groups as detected by IR could be responsible for the high density of very small microvoids. No such interference features have yet been detected in any a-Si:H or a-SiGe:H films.
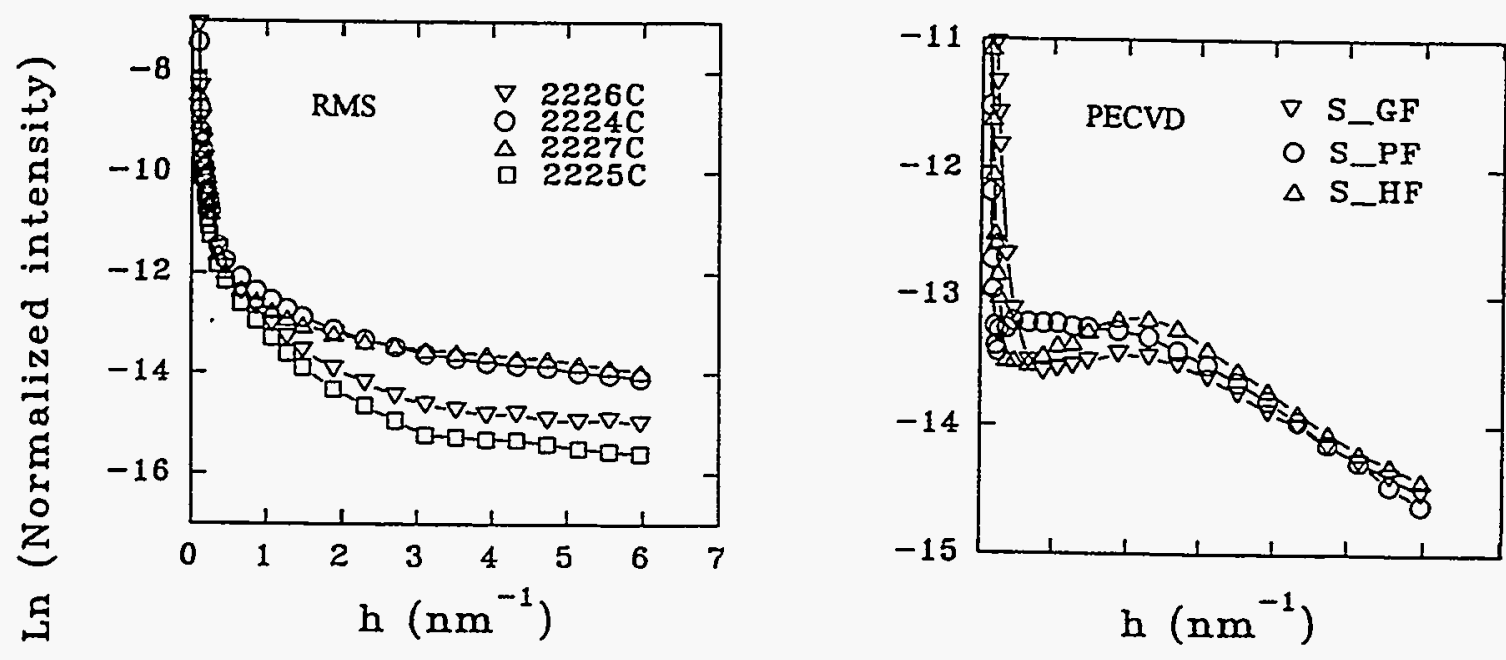

Fig. 9. SAXS scans from RMS and PECVD a-SiC:H alloys. 


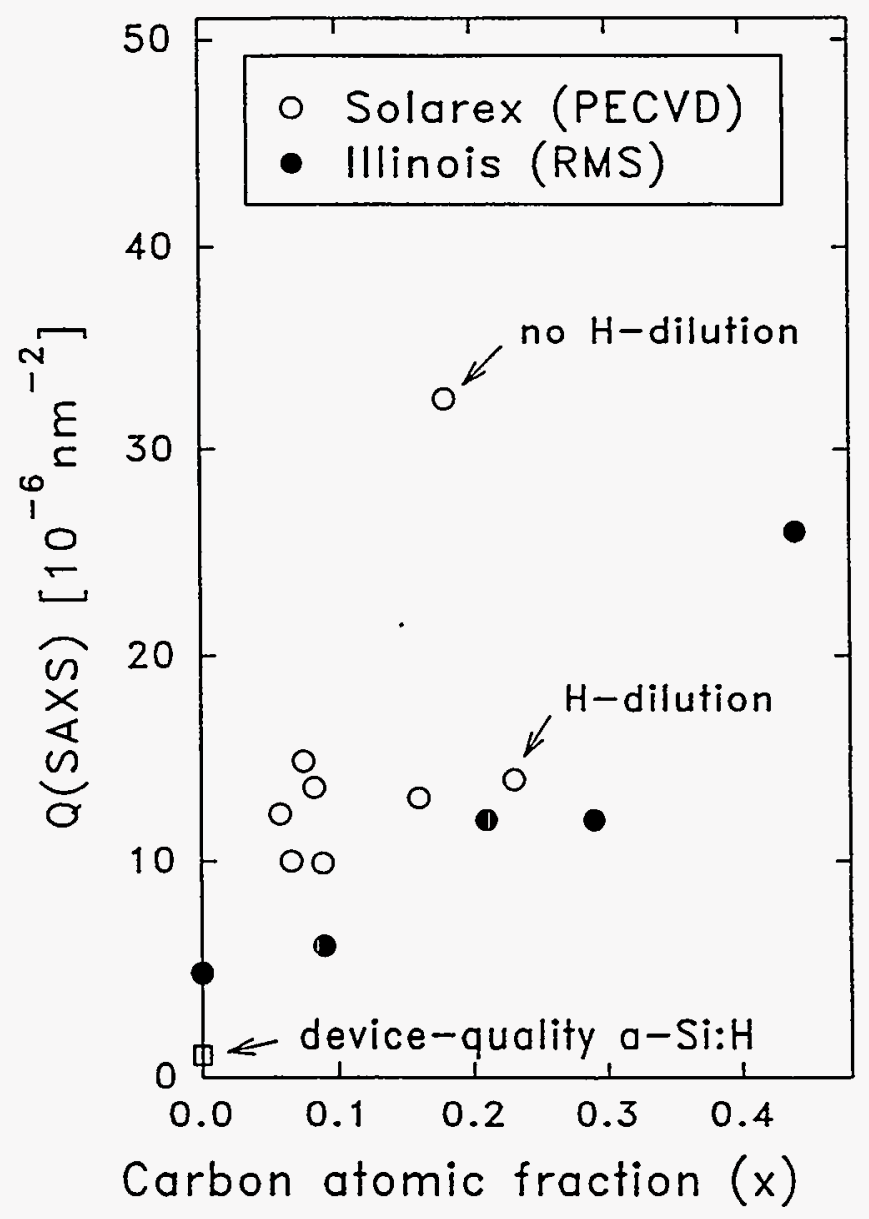

Fig. 10. Comparison of integrated SAXS intensities from a-SiC:H alloys prepared by two methods.

Table 3 summarizes all currently known information about the a-SiC:H alloys prepared by the two methods. Note the significantly smaller densities of the PECVD films for similar C content. The last six Solarex samples is the series of samples prepared as part of the NREL High-gap Team effort. Opto-electronic properties were supplied by two team members (Univ. of Illinois and Penn State) and both sets of data are included for comparison. 
Table 3. Comparison of properties of a-SiC:H prepared by RMS vs PECVD.

\begin{tabular}{|c|c|c|c|c|c|c|c|c|c|c|c|}
\hline Sample & $\begin{array}{r}T_{s} \\
\left({ }^{\circ} \mathrm{C}\right) \\
\end{array}$ & $X_{c}$ & $\begin{array}{l}\mathrm{C}_{\mathrm{H}} \\
(\mathrm{at} . \%)\end{array}$ & $\begin{array}{l}\mathrm{Eg} \\
(\mathrm{eV})\end{array}$ & $\begin{array}{l}\text { Urbach } \\
\text { Eo imeV) }\end{array}$ & $\begin{array}{l}\sigma_{\text {phow }}+ \\
\left(\Omega \mathrm{cm}^{-1}\right.\end{array}$ & $\begin{array}{c}\mu \tau \\
\left(\mathrm{cm}^{2} / \mathrm{s}\right)\end{array}$ & $\begin{array}{l}\text { DOSYCPMI } \\
\left(10^{15} \mathrm{~cm}^{-3}\right.\end{array}$ & $\begin{array}{r}\rho_{\text {fat }} \\
\left({\left.\mathrm{g} / \mathrm{cm}^{3}\right)}^{2}\right.\end{array}$ & $\begin{array}{c}Q^{\#} \\
\left(10^{-6} \mathrm{~nm}^{-2}\right)\end{array}$ & $Q_{0} / Q_{45}$ \\
\hline$-2225 \mathrm{C}$ & 275 & 0.0 & 13 & 1.67 & 48 & $1.4 \times 10^{-6}$ & - & 1.2 & 2.22 & 4.6 & 1.6 \\
\hline $.2226 \mathrm{C}$ & 275 & 0.09 & 14 & 1.71 & 53 & $1.0 \times 10^{-6}$ & .. & 6.3 & 2.17 & 5.9 & 1.2 \\
\hline$-2224 \mathrm{C}$ & 275 & 0.21 & 24 & 1.90 & 66 & $3.5 \times 10^{-7}$ & - & 10 & 2.08 & 12.0 & 1.3 \\
\hline$-2227 \mathrm{C}$ & 275 & 0.29 & 25 & 1.95 & 71 & $5.2 \times 10^{-8}$ & -- & 27 & 2.10 & 12.0 & 1.4 \\
\hline *S PF & 265 & 0.10 & - & -1.95 & 80 & .. & $<6 \times 10^{-10}$ & - & 2.03 & 15.7 & 1.1 \\
\hline *AS GF & 265 & 0.16 & - & -1.95 & $>110$ & .- & $1 \times 10^{-8}$ & - & 2.06 & 13.1 & 1.1 \\
\hline *S QF & 250 & 0.18 &. & -1.95 & 79 &.. & $1 \times 10^{-9}$ & - & 1.92 & 32.5 & 1.0 \\
\hline " S HF & 180 & 0.23 & .- & -1.95 & 69 & - & $4 \times 10^{-8}$ & .. & 2.05 & 14.0 & 1.2 \\
\hline - A $\mathrm{A} 3018-1$ & .. & 0.01 & 12.8 & 1.8 & 64 & $2.4 \times 10^{-6}$ & $5.3 \times 10^{-7}$ & 160 & 2.18 & 575 & 0.9 \\
\hline$\because A 3006-1$ & - & 0.09 & 16 & 1.9 & 50 & $7.1 \times 10^{-7}$ & $1.6 \times 10^{-7}$ & 4.8 & 2.10 & 9.9 & 1.1 \\
\hline$\because A 3019-2$ & .. & 0.06 & 14.6 & 1.95 & 63 & $1.4 \times 10^{-7}$ & $2.8 \times 10^{-8}$ & 170 & 1.98 & 12.3 & 1.0 \\
\hline$\because A 3068-1$ & - & 0.08 & - & 1.95 & $\ldots$ & $-2 \times 10^{-6}$ & $\ldots$ & - & 2.00 & 13.6 & 1.1 \\
\hline$\because A 3068-2$ & - & 0.08 & 23 & 1.9 & - & $-2 \times 10^{-4}$ & - & - & 2.03 & 14.9 & 1.1 \\
\hline$\because A 3005-1$ & $\ldots$ & 0.07 & 18 & 1.9 & -- & $-1 \times 10^{-6}$ & - & -- & 2.11 & 10.0 & 1.1 \\
\hline
\end{tabular}

* RMS film; ${ }^{* *}$ PECVD film: $+\sigma_{\text {der }}$ were all below $4 \times 10^{-12}$ (ohm $\left.\mathrm{cm}\right)^{-1}$ for RMS films; $\mu \tau$ were from $\sigma_{\text {proso }}$ \# no correction of alloy scattering due to lack of angle-independent behavior at high $h$. note: , the opto-electronic properties listed above for ' $A$ ' series samples were provided by Illinois Univ.

\begin{tabular}{|c|c|c|c|c|c|c|c|c|c|c|}
\hline \multirow[t]{2}{*}{ Sample } & \multirow{2}{*}{$\begin{array}{r}E_{03} \\
(\mathrm{eV}) \\
\end{array}$} & \multirow{2}{*}{$\begin{array}{l}E_{\text {TAUC }}(\mathrm{eV}) \\
2.0-2.4 \mathrm{cV}\end{array}$} & \multirow{2}{*}{$\begin{array}{l}E_{\text {TAUC }}(\mathrm{eV}) \\
2.3-2.6 \mathrm{eV}\end{array}$} & \multirow{2}{*}{$\begin{array}{l}E_{C \alpha d y}(e V) \\
2.7-3.1 \mathrm{eV}\end{array}$} & \multicolumn{2}{|r|}{$\mathrm{imeV}$} & \multicolumn{2}{|c|}{$\alpha_{(1.2 \mathrm{eV})}(\mathrm{cm})^{-1}$} & \multirow{2}{*}{$\begin{array}{l}\sigma_{\text {dhodo }}+ \\
\left(\Omega \mathrm{cm}^{-1}\right.\end{array}$} & \multirow{2}{*}{$\begin{array}{c}\mu \tau \\
\left(\mathrm{cm}^{2} / N\right) \\
\end{array}$} \\
\hline & & & & & annealed & saturated & annealed & saturated & & \\
\hline A3018-1 & 1.74 & 1.81 & 1.86 & 1.77 & 64 & 72 & 1.84 & 32.8 & $2.4 \times 10^{-6}$ & $1.62 \times 10^{-7}$ \\
\hline A3006-1 & 1.84 & 1.85 & 1.94 & 1.88 & 50 & 56 & 0.10 & 6.9 & $7.1 \times 10^{-7}$ & $5.25 \times 10^{-7}$ \\
\hline$A 3019-2$ & 1.94 & 1.92 & 2.02 & 1.92 & 63 & 70 & 0.62 & 12.5 & $1.4 \times 10^{-7}$ & $2.75 \times 10^{-8}$ \\
\hline
\end{tabular}

note: the opto-electronic properties listed above for ' $A$ ' series samples were provided by Pennsylvania state Univ. 


\subsection{SAXS from Related Materials}

\subsection{1 a-Ge:H}

Two sets of a-Ge:H films from Harvard were prepared to study the effects of electrode spacing and rf power and significant reductions in the SAXS can be obtained when moderate powers and small spacings are used. Table 4 summarizes the optoelectronic and SAXS characteristics of both sets of films. While Q's for a-Ge:H films prepared under these conditions are only slightly larger than values for device-quality aSi:H (see the lowest point at $x=1$ in Fig. 7), there is clear evidence of a small amount of oriented microstructure based on $\mathrm{Q}\left(0^{\circ}\right) / \mathrm{Q}\left(45^{\circ}\right)=2.2$ and 2.1 for the two lowest Q's in Table 4. Details of this work will be presented elsewhere ${ }^{30}$.

We have also examined a set of sputter-deposited a-Ge:H films from the group of B. Schroeder of the University of Kaiserslautern (UKL) in Germany. The a-Ge:H from UKL yields quite low SAXS signals as indicated by the data in Fig. 11 compared to one of the high-quality Harvard samples. However, note that the h-dependence is quite different from that of the Harvard PECVD material, i.e. much stronger intensities are observed at lower $\mathrm{h}$. This suggests larger scattering centers in the UKL material which may not be void-related but perhaps surface roughness-related. The analysis of codeposited films by the UKL group suggests that Al contamination is quite likely affecting the opto-electronic properties which are listed in Table 5 along with the SAXS results. The poorest quality film is \#2851 and it has the largest Q. Note that the lowest $\mathrm{Q}$ is quite similar to that of the lowest value from the Harvard material (Table 4).

Table 4. Opto-electronic and SAXS results from Harvard a-Ge:H films.

\begin{tabular}{|c|c|c|c|c|c|c|c|c|c|c|c|}
\hline Sample & $\begin{array}{l}\text { Electrode } \\
\text { spacing } \\
\text { (cm) }\end{array}$ & $\begin{array}{l}\text { Piasma } \\
\text { power } \\
\text { (W) }\end{array}$ & $\begin{array}{l}\mathrm{E}_{2} \\
\text { (cv) }\end{array}$ & $\begin{array}{l}\text { Eo } \\
(\mathrm{meV})\end{array}$ & $\begin{array}{c}\eta \mu \tau \\
\left(\mathrm{cm}^{2} \mathrm{v}^{-1}\right)\end{array}$ & $\sigma_{0} / \sigma$ & $\begin{array}{l}\alpha_{0.7} \\
(\mathrm{PDS}) \\
\left(\mathrm{cm}^{-1}\right)\end{array}$ & $\begin{array}{c}\mathrm{C}_{\mathrm{H}} \\
\text { from IR } \\
(\mathrm{at} \%)\end{array}$ & $\begin{array}{c}Q_{0} \\
\left(10^{-6} \mathrm{~nm}^{-2}\right)\end{array}$ & $Q_{0} / Q_{45}$ & $\begin{array}{l}I_{A} \\
\left(10^{-7}\right)\end{array}$ \\
\hline $\mathrm{H}-257$ & 3.2 & 10 & 0.54 & 61 & $2.1 \times 10^{-9}$ & $4.5 \times 10^{-4}$ & 65 & 3.6 & 43.3 & 2.7 & 1.6 \\
\hline H-258 & 2.0 & 10 & 0.56 & 54 & $6.0 \times 10^{-8}$ & $1.0 \times 10^{-2}$ & 34 & 3.8 & 3.8 & 3.5 & 2.0 \\
\hline $\mathrm{H}-259$ & 1.2 & 10 & 0.58 & 49 & $1.4 \times 10^{-7}$ & $3.1 \times 10^{-2}$ & 18.5 & 3.1 & 2.4 & 2.2 & 1.8 \\
\hline $\mathrm{H}-340$ & 1.4 & 12 & 0.49 & so & $4.8 \times 10^{-8}$ & $5.8 \times 10^{-3}$ & 13.4 & 4.4 & 4.9 & 1.9 & 1.6 \\
\hline H.-338 & 1.4 & 30 & 0.62 & 47 & $3.2 \times 10^{-7}$ & $1.2 \times 10^{-1}$ & 10.3 & 5.7 & 5.2 & 2.3 & 2.9 \\
\hline H-342 & 1.4 & 48 & 0.59 & 65 & $6.5 \times 10^{-8}$ & $9.7 \times 10^{-2}$ & 66 & 7.7 & 71.8 & 2.1 & 2.8 \\
\hline
\end{tabular}




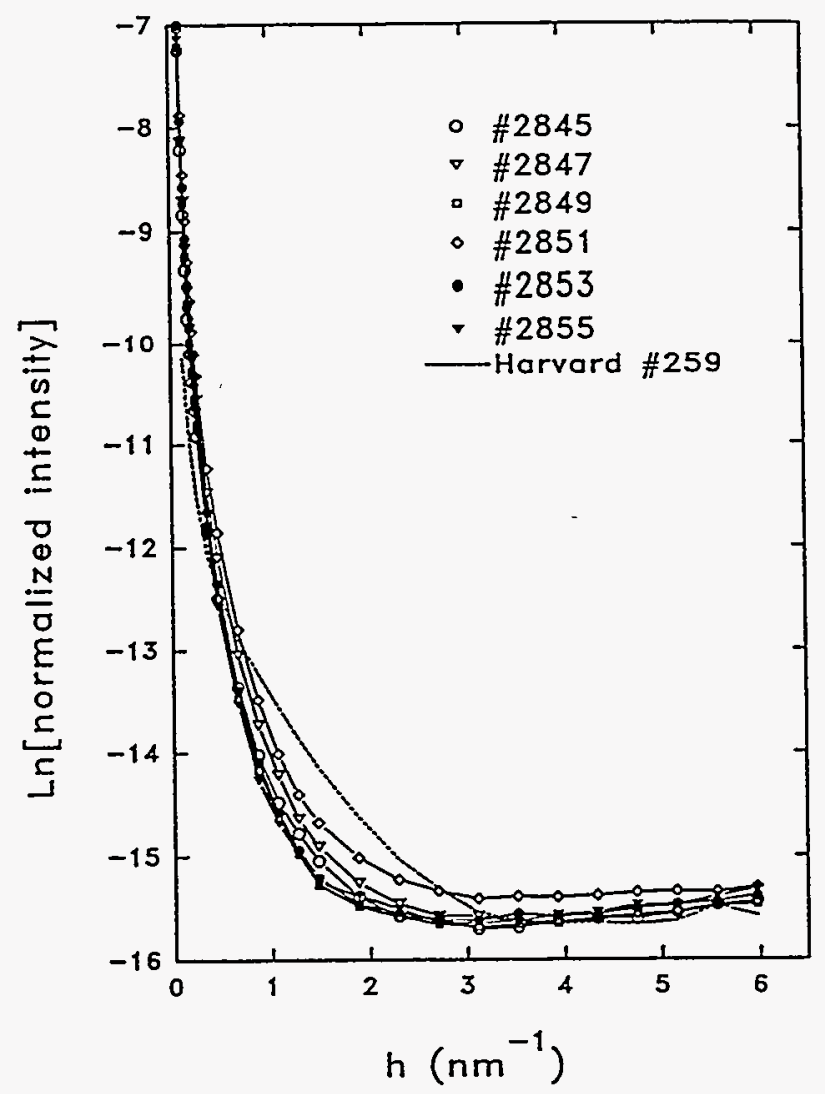

Fig. 11. SAXS from sputter-deposited a-Ge:H prepared at UKL. Data from the Harvard film prepared with the $1.2 \mathrm{~cm}$ electrode spacing is shown for comparison

Table 5. Opto-electronic and SAXS results from U. Kaiserslautern a-Ge:H films.

\begin{tabular}{|c|c|c|c|c|c|c|c|c|c|c|c|c|}
\hline Sample & $\begin{array}{c}\text { Power } \\
\text { (W) }\end{array}$ & $\begin{array}{c}\mathrm{T} \\
\left({ }^{\circ} \mathrm{K}\right) \\
\end{array}$ & $\begin{array}{l}\text { Ratce } \\
(\AA / s)\end{array}$ & $\begin{array}{c}\text { Ar } \\
\text { (mTorr) } \\
\end{array}$ & $\begin{array}{c}\mathbf{H} \\
\text { (mTorr) } \\
\end{array}$ & $\begin{array}{l}\sigma_{d} \\
(\Omega \mathrm{cm})^{-1}\end{array}$ & $\begin{array}{c}\mathrm{C}_{\mathrm{H}} \\
\text { (at.\%) }\end{array}$ & $\begin{array}{c}E_{0} \\
(m e V)\end{array}$ & $\begin{array}{c}\mathbf{Q}_{0} \\
\left(10^{-6} \mathrm{~nm}^{-2}\right)\end{array}$ & $Q_{0} / Q_{45}$ & $\begin{array}{c}I_{A} \\
\left(10^{-7}\right)\end{array}$ & $\begin{array}{c}\text { Thickness } \\
(\mu \mathrm{m})\end{array}$ \\
\hline$\# 2845$ & 100 & 475 & 5.1 & 0.9 & 0.9 & $3.00 \mathrm{E}-04$ & 4 & 45 & 2.5 & 1.6 & 1.3 & 3.7 \\
\hline$\# 2847$ & 100 & 475 & 4.9 & 1.3 & 1.3 & $2.40 \mathrm{E}-04$ & 4 & 47 & 2.9 & 1.1 & 1.5 & 3.5 \\
\hline$\# 2849$ & 100 & 475 & 4.6 & 0.5 & 0.7 & $1.40 \mathrm{E}-02$ & 4.5 & 44 & 2.1 & 1.4 & 1.5 & 3.3 \\
\hline$\# 2851$ & 200 & 475 & 10.0 & 0.5 & 0.7 & $2.90 \mathrm{E}-02$ & 4.5 & 65 & 3.6 & 1.2 & 1.9 & 3.9 \\
\hline$\# 23=3$ & 100 & 475 & 4.0 & 0.5 & 0.7 & $1.30 \mathrm{E}-02$ & 6 & 48 & 2.4 & 1.9 & 1.6 & 2.9 \\
\hline$\# 2855$ & 50 & 475 & 2.2 & 0.5 & 0.5 & $1.10 \mathrm{E}-04$ & 4.5 & 51 & 2.2 & 1.5 & 1.6 & 3.2 \\
\hline
\end{tabular}




\subsubsection{Boron-doped a-Si:H and a-SiC:H}

Two sets of boron-doped films have been provided by the group at Utrecht University. They represent our first systematic investigation of doped material. Figure 12 compares samples from the a-Si:H(B) series and the a-SiC:H(B) series to demosntrate the SAXS-detected changes induced by adding $\mathrm{B}_{2} \mathrm{H}_{6}$ to the PECVD plasma. The ratios given in the figure refer the gas flow ratios of $1 \% \mathrm{~B}_{2} \mathrm{H}_{6}$ in $\mathrm{H}_{2} /$ pure $\mathrm{SiH}_{4}$ (5 sccm, constant). The data show increases in the SAXS due to $\mathrm{B}$ incorporation. Table 6 lists the SAXS and flotation data as well as $B$ and $C$ contents determined by electron-probe micro-analysis (EPMA) at NREL. The B contents do not appear systematic with the gas flow ratios and disagree with systematic behavior of other properties such as conductivity activation energy, band-gap, and IR. This is likely due to $\mathrm{B}$ contents near the sensitivity limit of the EPMA. The tilting ratios are all unity within experimental error $( \pm 0.1)$ and this demonstrates no oriented microstructure is present in any of the films.

There are two columns in Table 6 for the flotation density because for the a$\mathrm{Si}: \mathrm{H}(\mathrm{B})$ series we were able to obtain values from flakes that were peeling from the glass substrates $\left(\rho_{\mathrm{gl}}\right)$ as well as from film removed from the Al-foil by acid etching $\left(\rho_{\mathrm{Al}}\right)$. The consistency of these two sets of numbers (within $0.01 \mathrm{~g} / \mathrm{cm}^{3}$, our experimental uncertainty in this method), is a good indication of little difference in the films codeposited on glass and the SAXS Al-foil. As can be seen the densities are dramatically lower than those of diamond-like $\mathrm{Si}_{\mathrm{I}-\mathrm{x}} \mathrm{C}_{\mathrm{x}}$ (about $2.6 \mathrm{~g} / \mathrm{cm}^{3}$ for $\mathrm{x}=0.27$ ) [or for graphiticlike $\mathrm{SiC}$ (about $2.3 \mathrm{~g} / \mathrm{cm}^{3}$ for $\mathrm{x}=0.27$ )]. Assuming a simple two-phase microstructure of voids plus the amorphous matrix, the size of the Q's in the SiC alloys $\left(\sim 70 \times 10^{-6} \mathrm{~nm}^{-2}\right)$ is consistent with void volume fractions near 15-20\%. The total bonded $\mathrm{H}$ content are not yet available. Further details of this study will be presented by our collaborators ${ }^{31}$.

\subsubsection{Microcrystalline Si:H}

The group at the Univ. of Illinois supplied a few samples of microcrystalline $(\mu \mathrm{c})$ $\mathrm{Si}: \mathrm{H}$ samples for investigation by SAXS. These are our first studies of this type of material. The samples were prepared by RMS and they were checked by $x$-ray diffraction (XRD) for the presence of the $\mu \mathrm{c}$ state. As shown in Table 7, two of the samples were completely amorphous but the other four showed only the $\mu \mathrm{c}$ state. Also the table shows $\mathrm{H}$ contents determined by SIMS analysis and the values remain near 10 at.\% in the $\mu \mathrm{c}$ state. Figure 13 shows SAXS curves for one of the $\mu \mathrm{c}-\mathrm{Si}: \mathrm{H}$ samples where one can see extremely strong signals as well as a decrease in the signals with time (stored in air at room temperature). This instability is associated with oxygen 

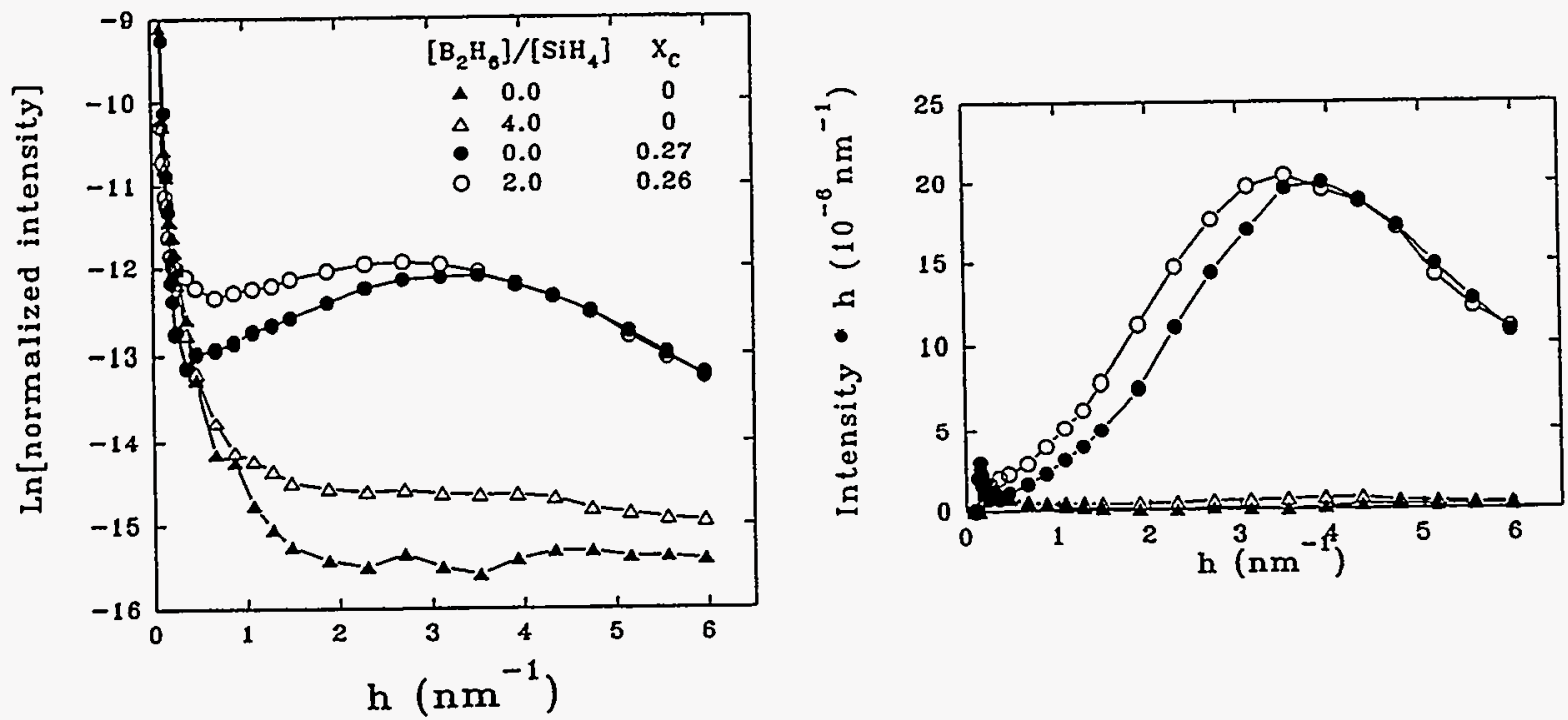

Fig. 12. Effect of B doping on the SAXS of a-Si:H and a-SiC:H films.

Table 6. SAXS, flotation densities and other results for B-doped a-Si:H and a-SiC:H films from Utrecht Univ.

\begin{tabular}{|c|c|c|c|c|c|c|c|c|c|}
\hline Sample & $\begin{array}{r}\mathrm{B}_{2} \mathrm{H}_{6}+\mathrm{H}_{2} \\
(\mathrm{SCCM})\end{array}$ & $\begin{array}{l}X_{C} \\
\text { (at. }\end{array}$ & $\begin{array}{r}X_{B} \\
\text { ction) }\end{array}$ & $\begin{array}{c}t \\
(\mu m)\end{array}$ & $\begin{array}{c}Q_{0} \\
\left(10^{-6} \mathrm{~nm}^{-2}\right)\end{array}$ & $Q_{0} / Q_{45}$ & $\begin{array}{l}\text { 'LM } \\
\left(10^{-7}\right)\end{array}$ & $\begin{array}{l}\rho_{A l} \\
\quad(g / c m\end{array}$ & $\begin{array}{l}\rho_{g l} \\
\left.3^{3}\right)\end{array}$ \\
\hline P402 & 0 & 0.27 & $<0.005$ & 0.56 & 69 & $1.1^{\circ}$ & a & 1.72 & - \\
\hline P406 & 0.5 & 0.27 & $<0.005$ & 1.28 & 73 & 1.1 & a & 1.70 & - \\
\hline P395 & 5 & 0.27 & $<0.005$ & 1.21 & 70 & 1.0 & a & 1.72 & - \\
\hline P450 & 10 & 0.26 & 0.012 & 0.65 & 77 & 1.1 & a & 1.76 & -- \\
\hline P460 & 15 & 0.28 & 0.003 & 0.65 & 67 & 1.1 & a & 1.73 & -- \\
\hline P455 & 20 & 0.25 & 0.005 & 0.68 & 66 & 1.1 & a & 1.75 & -- \\
\hline P449 & 0 & 0 & $<0.005$ & 0.77 & 1.3 & 1.0 & 1.7 & 2.19 & 2.18 \\
\hline P453 & 5 & 0 & $<0.005$ & 0.73 & 2.5 & 1.1 & 2.4 & 2.17 & 2.18 \\
\hline P454 & 10 & 0 & $<0.005$ & 0.78 & 1.6 & 1.1 & 2.4 & 2.16 & 2.16 \\
\hline P448 & 20 & 0 & $<0.005$ & 0.85 & 3.0 & 1.1 & 2.6 & 2.14 & 2.13 \\
\hline P468 & 0 & 0 & $<0.005$ & 1.33 & 0.7 & 0.9 & 1.3 & 2.23 & 2.22 \\
\hline
\end{tabular}

a No Laue monotonic background correction was made for these samples. 

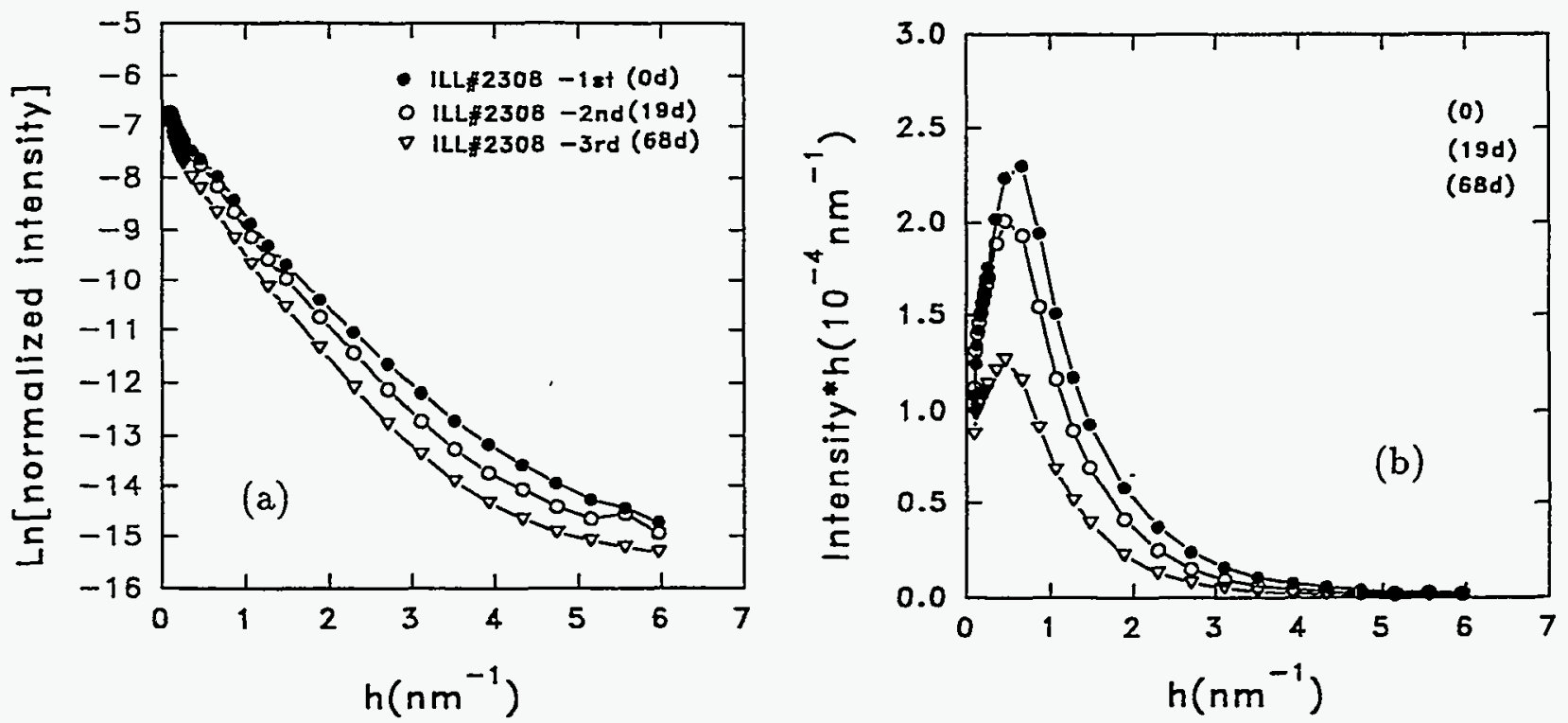

Fig. 13. (a) SAXS intensity from $\mu \mathrm{c}-\mathrm{Si}: \mathrm{H}$ in the as-received state and after storage in air for increasing times; (b) Ixh plots showing the clear decrease in $Q$ (area under curves) with time.

Table 7. SAXS and flotation density results from $\mu \mathrm{c}-\mathrm{Si}: \mathrm{H}$ films from Univ. of Illinois.

\begin{tabular}{|c|c|c|c|c|c|c|c|}
\hline Sample & $\begin{array}{c}\text { H content } \\
\text { (at.\%) }{ }^{*}\end{array}$ & $\begin{array}{l}\text { Density } \\
\left(\mathrm{g} / \mathrm{cm}^{3}\right)\end{array}$ & $\begin{array}{c}Q_{0} \\
\left(10^{-6} \mathrm{~nm}^{-2}\right)\end{array}$ & $\mathrm{Q}_{0} / \mathrm{Q}_{45}$ & $\begin{array}{c}\mathrm{I}_{\mathrm{A}} \\
\left(10^{-7}\right)\end{array}$ & $\mathrm{XRD}$ & $\begin{array}{l}\text { Thickness } \\
(\mu \mathrm{m})\end{array}$ \\
\hline$\# 2297 B$ & $\sim 10 \%$ & 2.19 & 490 & 5.0 & - & $\mu \mathrm{c}$ & 1.2 \\
\hline$\# 2298 B$ & $\sim 10 \%$ & 2.13 & 150 & 5.4 & - & $\mu \mathrm{c}$ & 2.0 \\
\hline$\# 2299 B$ & $\sim 9 \%$ & 2.12 & 47 & 2.4 & 1.22 & amorphous & 1.6 \\
\hline$\# 2300 \mathrm{~B}$ & $\sim 7 \%$ & 2.10 & 43 & 2.3 & 0.98 & amorphous & 1.4 \\
\hline $\begin{array}{l}\text { \#2308 } \\
\text { (19 days later) } \\
\text { (68 days later) }\end{array}$ & $?$ & 2.14 & $\begin{array}{l}320 \\
260 \\
150\end{array}$ & 5.4 & - & $\mu \mathrm{c}$ & 1.7 \\
\hline $\begin{array}{l}\# 2307 \\
\text { (18 days later) } \\
\text { (79 days later) }\end{array}$ & $?$ & 2.18 & $\begin{array}{l}420 \\
380 \\
310\end{array}$ & 2.7 & - & $\mu \mathrm{c}$ & 1.4 \\
\hline
\end{tabular}

* SIMS analysis 
incorporation as detected by IR and by the SIMS analysis. Note that the integrated SAXS intensities as listed in Table 7 are as high as $490 \times 10^{-6} \mathrm{~nm}^{-2}$, which is about three orders of magnitude larger than typical values for device-quality a-Si:H (see Table 1). Note that this increase occurs without substantial increases in the density deficits, based on the flotation densities shown in the table. Strong tilting effects show that the microstructure is highly oriented so that a columnar-type microstructure is implicated and this probably leads to the post-deposition oxidation. To account for such strong SAXS and the relatively small density deficits requires low-density (and probably heavily hydrogenated) boundaries between the micro-crystallites.

\subsubsection{Annealing of a-Si:H}

Four samples of a-Si:H prepared by RF sputtering at Iowa State (Shinar's group) have undergone a systematic series of anneals with SAXS and IR carried out after each anneal. The IR measurements were made with films on c-Si substrates (co-deposited with the SAXS films on Al-foil). Annealing at $350^{\circ} \mathrm{C}$ and above sharply increased the integrated SAXS intensity $Q$, although the film density remained nearly constant. Incipient formation of $\mu \mathrm{c}-\mathrm{Si}$ domains by $\mathrm{Si}$ diffusing into the $\mathrm{Al}$ substrate is insufficient to account for the increased SAXS. Rather the close correlation between $Q$ and the Sibonded $\mathrm{H}$ content $\mathrm{C}_{\mathrm{H}}$, as shown in Fig. 14, suggests that it more likely results from migration of $\mathrm{H}$ released from $\mathrm{Si}-\mathrm{H}$ bonds to deep traps at microvoid surfaces and its accumulation as $\mathrm{H}_{2}$ in the isolated voids. The density of the $\mathrm{Si}$ network then increases as its $\mathrm{H}$ content decreases, and the void sizes increase as hydrogen accumulates in them. The size distributions shown in Fig. 15 are consistent with this interpretation, and consistent with the known characteristics of $\mathrm{H}$ diffusion in a-Si: $\mathrm{H}^{32,33}$.

Annealing for $6 \mathrm{~h}$ at $430^{\circ} \mathrm{C}$ also resulted in some crystallization sufficient to be detected by XRD and Raman spectroscopy. Following $36 \mathrm{~h}$ at that temperature, the Raman and XRD indicated that about 50 vol\% of the film was still amorphous. Auger profiles showed that $\mathrm{Al}$ had diffused throughout the film to a level of 2 to 3 at.\%. However an observed reduction in tilt angle dependence is probably not due to filling of the voids by the diffusing $\mathrm{Al}$ but rather to the relaxation and reduction of the columnar-like microstructure. Further details of this work are presented elsewhere ${ }^{34}$. 


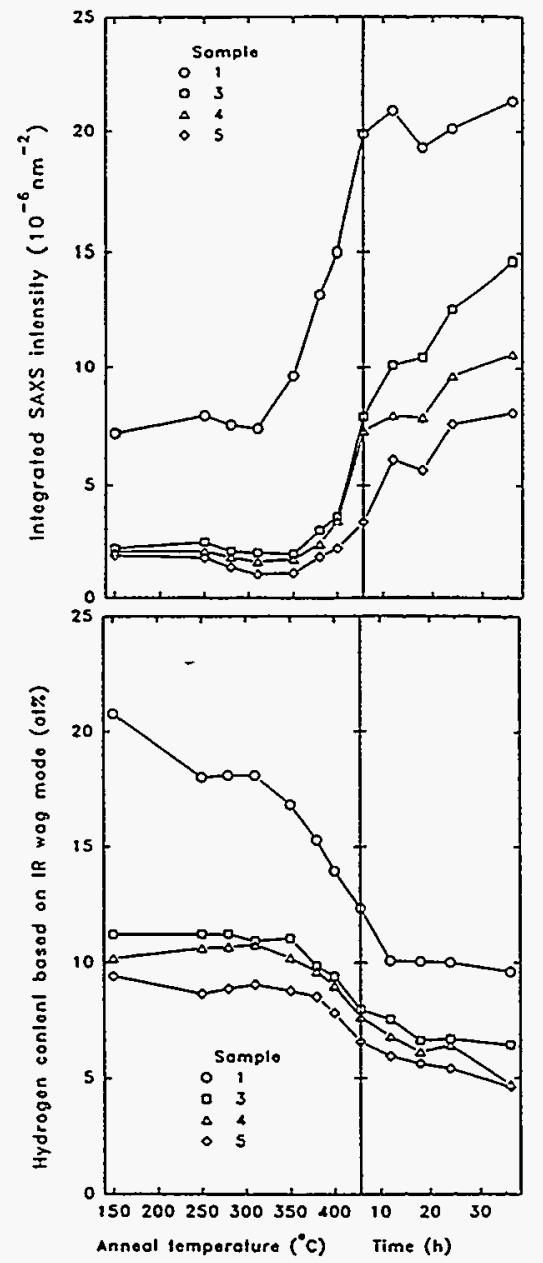

Fig. 14. Integrated SAXS intensities and Si-bonded $H$ contents (from IR) versus annealing temperature and time.
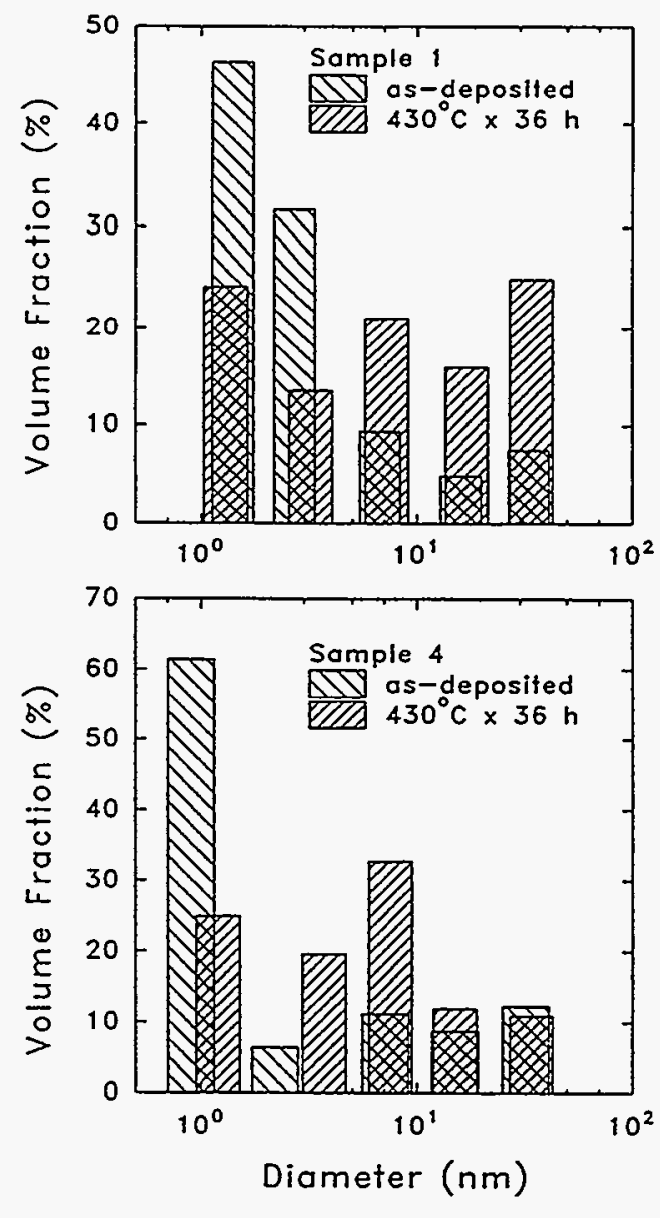

Fig. 15. Distributions of void sizes in samples 1 and 4 before and at the conclusion of the annealing.

\subsection{5 a-SiSe:H}

A set of seven samples of $a-\mathrm{Si}_{1-\mathrm{x}} \mathrm{Se}_{\mathrm{x}}: \mathrm{H}$ was prepared by PECVD with silane and $\mathrm{H}_{2} \mathrm{Se}$ by the group at Texas A\&M Univ. This material is being considered by them (with support by EPRI) as an alternative high-gap material. Table 8 lists the $\mathrm{H}_{2} \mathrm{Se}$ flow rates, Se contents, film thicknesses, Tauc band-gaps, conductivities, flotation densities and SAXS results for this set of films. Some of the thicknesses are quite small so there are corresponding large uncertainties in the Q's and $I_{A}$ 's for these films. However, in general the Q's are quite small and several are comparable to the values listed in Table 1 for a-Si:H. There is also no evidence of an oriented microstructure. The sample with the largest band-gap of $1.78 \mathrm{eV}$, has the poorest photoconductivity but the SAXS is not significantly larger than the other samples, suggesting that other defects are likely responsible for the degradation. It is interesting that that addition of Se does not induce as strong an increase in the SAXS compared to PECVD-prepared a-Si $\mathrm{i}_{1-x} \mathrm{C}_{\mathbf{x}}: \mathrm{H}$ for similar values of $x$ (see Fig. 10 and Table 3 ). 
Table 8. SAXS and other results from a-SiSe:H films from Texas A\&M Univ.

\begin{tabular}{|c|c|c|c|c|c|c|c|c|c|c|}
\hline Sample & $\begin{array}{l}\mathrm{H}_{2} \mathrm{Sc} \\
\mathrm{sccm}\end{array}$ & $\begin{array}{c}\mathbf{x}_{\mathrm{Se}} \\
(\mathrm{at} \% \text { ) }\end{array}$ & $\begin{array}{c}\mathbf{E}_{g} \\
(\mathrm{eV})\end{array}$ & $\begin{array}{l}\sigma_{\mathrm{ph}}\left(10^{-5}\right) \\
(\Omega \mathrm{cm})^{-1}\end{array}$ & $\begin{array}{l}\sigma_{d}\left(10^{-9}\right) \\
(\Omega \mathrm{cm})^{-1}\end{array}$ & $\begin{array}{l}P_{\text {flot }} \\
\left(\mathrm{g} / \mathrm{cm}^{3}\right)\end{array}$ & $\begin{array}{c}Q_{0} \\
\left(10^{-6} \mathrm{~nm}^{-2}\right) \\
\end{array}$ & $Q_{0} / Q_{45}$ & $\begin{array}{r}I_{A} \\
\left(10^{-i}\right) \\
\end{array}$ & $\begin{array}{c}\text { Thickness } \\
(\mu \mathrm{m})\end{array}$ \\
\hline Lin\#1 & 0.097 & 2.78 & 1.69 & 2.01 & 2.41 & 2.34 & 0.28 & $\sim 1$ & 1.0 & 1.18 \\
\hline Lin\#2 & 0.280 & 6.34 & 1.75 & 0.58 & 0.59 & 2.47 & 0.52 & -1 & 1.2 & 1.29 \\
\hline Lin\#3 & 0.141 & 3.85 & 1.71 & 1.79 & 1.47 & 2.38 & 3.33 & -1 & 2.8 & 0.50 \\
\hline Lin\#4 & 0.422 & 5.83 & 1.77 & 0.36 & 1.10 & 2.46 & 0.73 & $\sim 1$ & 1.9 & 0.61 \\
\hline Lint\#5 & 0.072 & 3.41 & 1.71 & 5.91 & 5.64 & 2.37 & 4.42 & -1 & 0.9 & 0.29 \\
\hline Lin\#6 & 0.590 & 8.03 & 1.78 & 0.09 & 0.77 & 2.53 & 0.41 & -1 & 1.6 & 0.68 \\
\hline Lin $\neq 7$ & 0.127 & 2.97 & 1.72 & 2.27 & 2.39 & 2.35 & 0.30 & -1 & 1.2 & 0.65 \\
\hline
\end{tabular}

\subsection{SAXS Interpretation and Methodology}

\subsubsection{Two-phase microstructure calibration}

The integrated intensity, $\mathrm{Q}, \mathrm{can}$ be converted into a volume fraction of scattering centers under the assumption of a two-phase microstructure provided there is no preferred orientation of the microstructure. For our definition of the normalized intensity ${ }^{12}, I$, the conversion of $Q$ to a volume fraction, $V_{f}$, can be made from

$$
\mathrm{Q}=\int \mathrm{hIdh}=(\kappa / \mu)(\Delta \mathrm{n})^{2} \mathrm{~V}_{\mathrm{f}}\left(1-\mathrm{V}_{\mathrm{f}}\right)
$$

where $\Delta \mathrm{n}$ is the electron density difference in the two phases of the sample, $\mu$ is the linear absorption coefficient of the sample for the x-rays used, and $\kappa$ is a constant determined by the geometry of the SAXS slit system ${ }^{35}$. For our current geometry the value of $\kappa$ can be calculated as $1.30 \times 10^{-35} \mathrm{~cm}^{3}$. We decided to check this value by performing experiments with model two-phase samples where known values of $V_{f}, \Delta n$, and $\mu$ could be obtained by careful sample preparation.

Two well-known metallurgical systems that form a two-phase precipitate-matrix microstructure are $\mathrm{Al}-\mathrm{Ag}$ and $\mathrm{Cu}-\mathrm{Be}$. $\mathrm{A} \mathrm{Cu}-\mathrm{Be}$ alloy of known composition (12 at.\% $\mathrm{Be}$ ) was available commercially and an $\mathrm{Al}-4$ at.\% $\mathrm{Ag}$ was prepared in house. Careful, systematic heat treatments allowed preparation of known volume fractions of precipitates of phases that could be confirmed by XRD: $\mathrm{AlAg}_{2}$ (hcp structure) in Al-Ag and $\mathrm{CuBe}$ (cubic $\mathrm{CsCl}$ structure) in $\mathrm{Cu}-\mathrm{Be}$. In addition, a sample comprised of a known volume fraction of $\mathrm{Sb}_{2} \mathrm{O}_{3}$ particles in a polymeric matrix was available as a third 
standard. The results of the SAXS experiments with these three type of standards are shown in Fig. 16 where theoretical Q's, based on the above value of $\kappa$, and the expected values of $V_{f}, \Delta \mathrm{n}$, and $\mu$ for the samples are compared with the experimental $Q$ 's. The solid line with a slope of $45^{\circ}$ corresponds to exact agreement and the data are in reasonable agreement with this line. Based on the scatter of the data in this figure and our estimated uncertainties in the theoretical Q's of the standards, the above value of $\kappa$ has been established within $\pm 15 \%$.

The application of this calibration to a two-phase system consisting of microvoids in an amorphous $\mathrm{Si}-\mathrm{H}$ matrix leads to the prediction that a $1 \%$ void fraction in a film with 10 at\% $\mathrm{H}$ bonded in the matrix will yield a $Q$ of about $4 \times 10^{-6} \mathrm{~nm}^{-2}$ (the units used in our tables and plots throughout this document). The predicted values of $Q$ for a void fraction of $1 \%$ in a- $\mathrm{Si}_{1-\mathrm{x}} \mathrm{Ge}_{\mathrm{x}}: \mathrm{H}$ for $\mathrm{x}=0.5$ and $\mathrm{x}=1$ are about 6 and $8 \times 10^{-6} \mathrm{~nm}^{-2}$, which are larger due to the effect of larger $\Delta n$ 's. Since we are able to measure a $Q$ as small as $0.1 \times 10^{-6} \mathrm{~nm}^{-2}$ for a film of about $3 \mu \mathrm{m}$ thickness (see Table 1), this demonstrates our ability to detect void fractions as low as about $0.025 \%$ in $\mathrm{a}-\mathrm{Si}: \mathrm{H}$ and somewhat smaller in SiGe alloys.

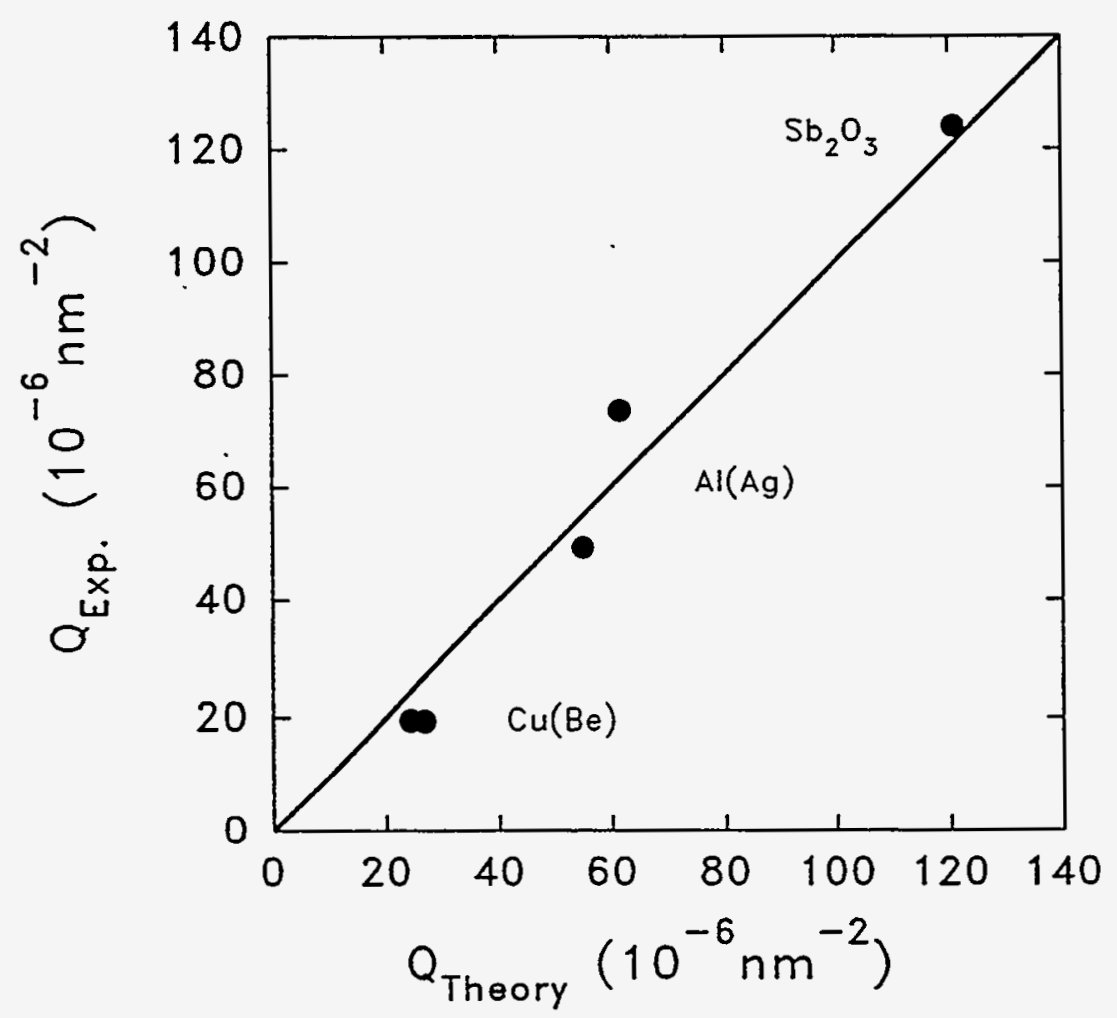

Fig. 16. Comparison of theoretical and experimental SAXS Q's for two-phase calibration samples. The solid line at $45^{\circ}$ is that expected for exact agreement between theory and experiment. 


\subsubsection{Density deficits and $\mathrm{H}$ alloying of a-Si:H}

It is known that for high-quality c-Si the mass density is $2.3293 \mathrm{~g} / \mathrm{cm}^{3}$. Comparison of the flotation densities in Table 1 with this value shows significant density deficits of several $\%$ are present, even in high quality samples with low Q's and, therefore, low void fractions (well below $1 \%$ ). These deficits have been accounted for with a simple Halloying model ${ }^{36}$ based on several samples with known bonded $\mathrm{H}$ contents and known void fractions from SAXS. The only adjustable parameter in the model is the atomic volume occupied by the bonded $\mathrm{H}$ atom, $\Omega_{\mathrm{H}}$, expressed as a ratio to that of $\mathrm{Si}$, $\alpha=\Omega_{\mathrm{H}} / \Omega_{\mathrm{Si}}$. Results of this analysis are shown in Fig. 17 where one can see a reasonably good fit to the matrix densities assuming $\alpha=0.4$, i.e. the bonded $\mathrm{H}$ occupies only $40 \%$ that of a Si atom. Such a value can be shown to be consistent with the much shorter Si$\mathrm{H}$ bond length $(0.1480 \mathrm{~nm})$ vs that of $\mathrm{Si}-\mathrm{Si}(0.2352 \mathrm{~nm})^{36}$.

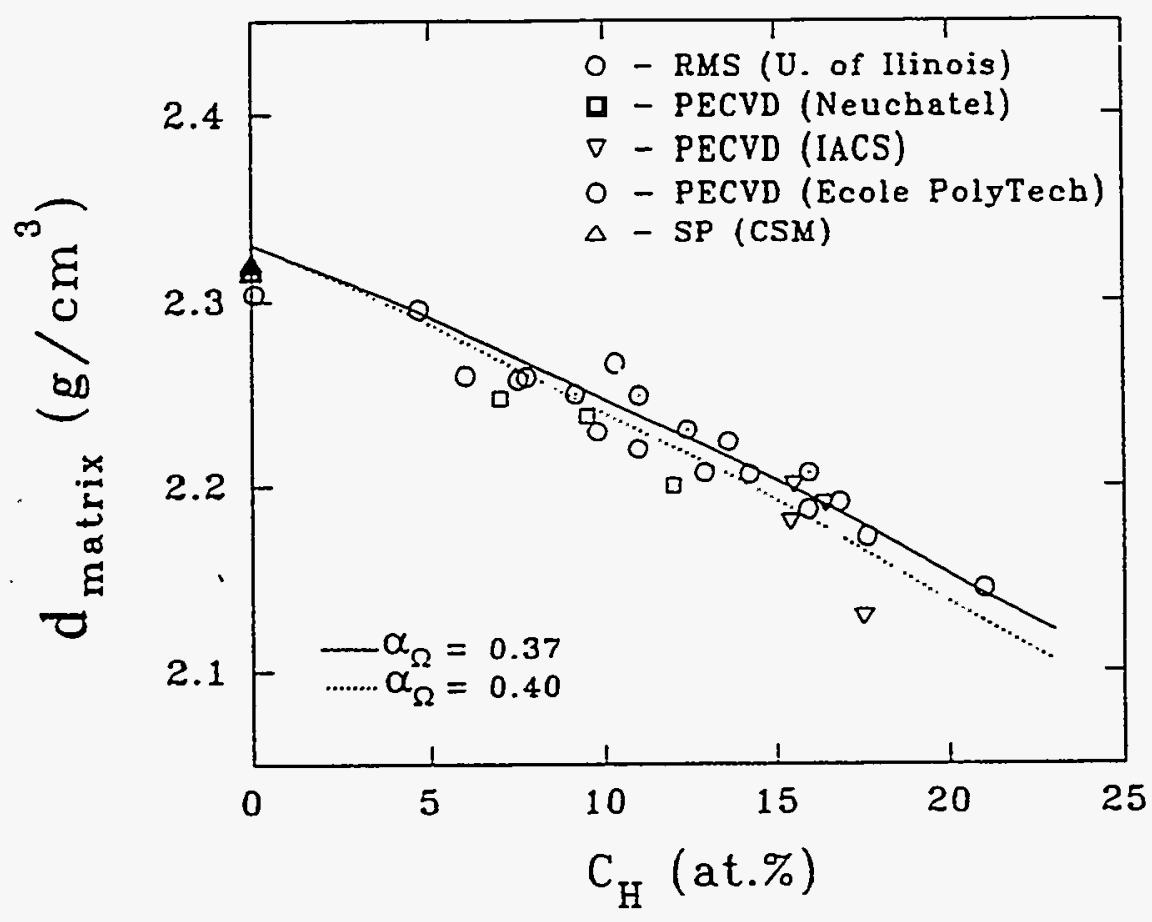

Fig. 17. Matrix densities of a-Si:H films from flotation densities, corrected for small void fractions obtained from SAXS. Solid and dashed lines are fits based on a model with the adjustable parameter $\alpha$ (ref. 36). 


\subsubsection{SAXS sytem flaw}

An experimental problem with the SAXS apparatus was discovered in June, 1992, during a careful examination and adjustment of the system alignment. The cause of the problem was a design flaw in the commercial SAXS system obtained for our research. The flaw was quickly repaired and a systematic study of the effect of the flaw on previous SAXS data was made. The effect of the flaw was to produce an apparent decrease in the SAXS signal with increasing angle above a certain angle. This effect therefore caused errors in the shape of the SAXS curves above this angle. The errors in void fractions and size distributions were relatively small for all samples showing relatively strong SAXS corresponding to void fractions above about 0.5 volume $\%$ $\left(\mathrm{Q} \simeq 2 \times 10^{-6} \mathrm{~nm}^{-2}\right)$, while those for the more weakly scattering material (typically devicequality PECVD films) were larger. The reanalyzed size distributions of the latter type of samples show significantly smaller fractions of the very small voids (about $1 \mathrm{~nm}$ diameter), a slight shift in their size toward $2 \mathrm{~nm}$, and a corresponding increase in the fractional contribution from larger scattering centers (about 2 to $3 \mathrm{~nm}$ diameter). As discussed in section 4.1 (see Fig. 5), the origin of this larger-scale microstructure is not yet established.

\subsubsection{Diffuse scattering contributions}

A new feature in most of the SAXS curves that was detected after repair of the flaw is an angle-independent, i.e. diffuse, scattering behavior at the larger angles, as seen in Fig.1, such that constant, but quite different, levels of scattering are found for different samples. In addition, for some of the weakest scattering samples, a slight increase in SAXS with increasing angle at the largest angles was found. Possible physical explanations for these observations have been considered and verified with several experiments ${ }^{36}$. The most important effect that has come to light is that due to random alloy scattering (Laue monotonic scattering ${ }^{13,14,35}$ ) and it is quite significant for the a-SiGe:H alloys. This effect also produces an observable contribution due to $\mathrm{H}$ alloying in a-Si:H. The theory of this effect for a random binary alloy with elements $\mathrm{A}$ (atomic fraction $\mathrm{x}$ ) and $\mathrm{B}$ (atomic fraction 1-x) yields the simple result that the diffuse intensity is given (in electron units) by $J_{L M}=x(1-x)\left(Z_{A}-Z_{B}\right)^{2}$, where $Z$ is the atomic number. A similar, but more complex expression can be derived for a random ternary alloy, that can be compared to experimental data from a-SiGe:H and a-SiC:H alloys. Theoretical predictions are displayed in Fig. 18 where one can see the relative sizes of the intensities for various alloy compositions, including a-Si:H along the left ordinate. 


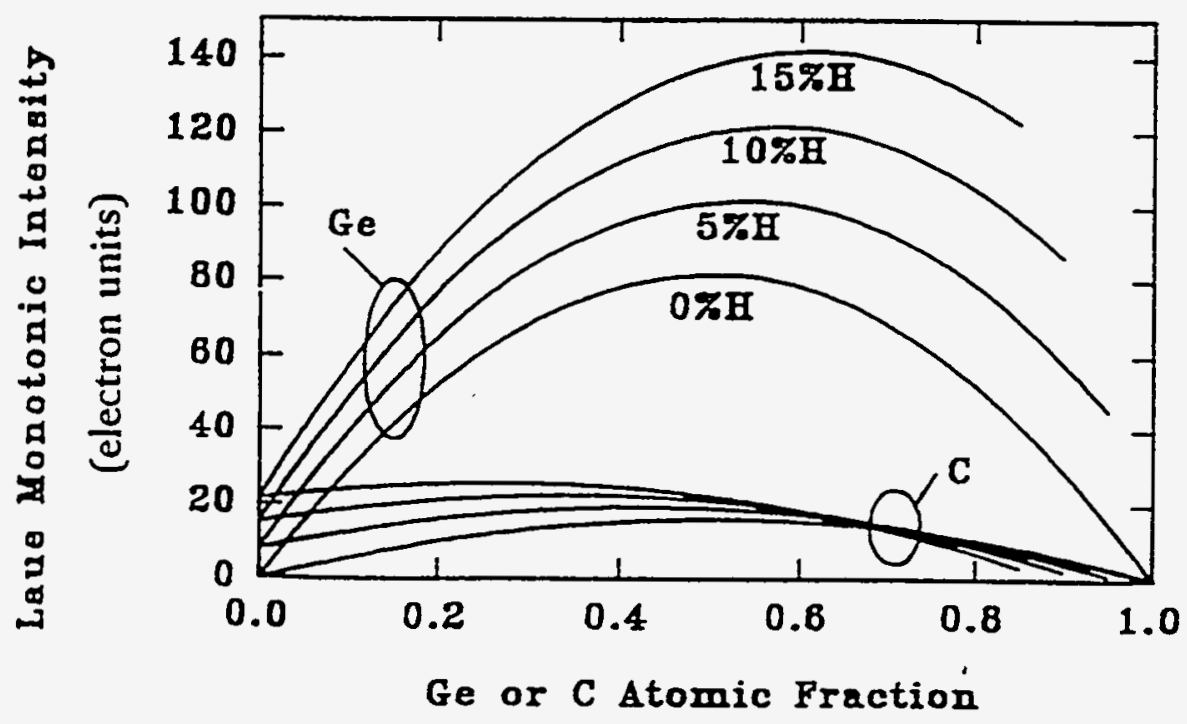

Fig. 18. Theoretical Laue monotonic diffuse scattering contributions for random a$\mathrm{SiGe:H}$ and a-SiC:H alloys with various $\mathrm{H}$ contents.

Experimental values of the alloy diffuse scattering, $I_{A}$, from about 50 films of aSiGe:H alloys, including the a-Si:H and a-Ge:H end points are shown in Fig. 19. The solid line is a least-square fit of a quadratic to the data while the dashed line represents the theoretical Laue monotonic scattering for random alloys (converted from the electron units of Fig. 18 to our normalized SAXS intensity units). Clearly, the experimental values are much larger than predicted and this is solid evidence for shortrange alloy clustering in this alloy system. Note that there is considerable scatter for several data points near $\mathrm{x}=0.7$, well outside the experimental uncertainty indicated by the error bars. This suggests that the degree of clustering depends on the deposition process and that it may be controllable. Evidence of non-random a-SiGe:H alloys has been found by other groups using Raman scattering ${ }^{37,38}$.

The diffuse scattering contribution from a-SiC:H alloys prepared by PECVD can not be investigated due to the angle-dependent scattering that occurs up the highest angles (Fig. 9) such that a background level cannot be accurately determined. However, the RMS films do approach well-defined, angle-independent levels (Fig. 9) and the alloy scattering results from these films are shown in Fig. 20. Comparison with the predicted behavior based on random alloying, assuming a $\mathrm{H}$ content of 15 at.\% (the dashed curve), shows evidence for short-range clustering such that are more $\mathrm{Si}-\mathrm{Si}$ and $\mathrm{C}-\mathrm{C}$ bonds than expected for a random alloy. There may be significant contributions also from $\mathrm{H}$ clustering associated with non-statistical quantities of $\mathrm{C}-\mathrm{H}_{\mathrm{n}}$ groups where $\mathrm{n}=2$ and 3. Further correlation with IR data is needed. 


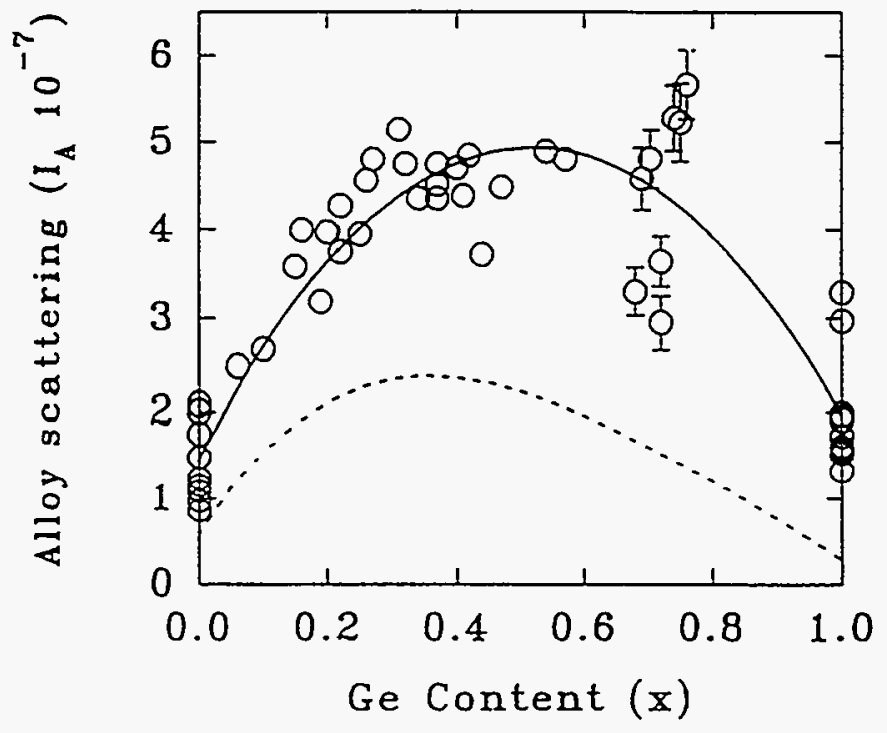

Fig. 19. Diffuse scattering intensities from a-Si ${ }_{1-x} \mathrm{Ge}_{x}: \mathrm{H}$ alloys (all prepared by PECVD).

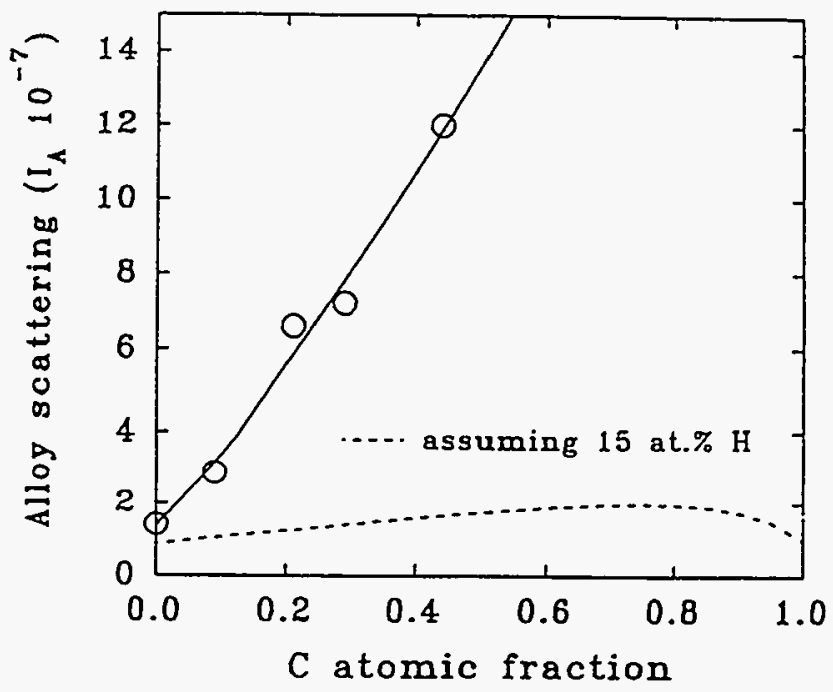

Fig. 20. Diffuse scattering intensities from $\mathrm{a}-\mathrm{Si}_{1-\mathrm{x}} \mathrm{C}_{\mathrm{x}}: \mathrm{H}$ alloys prepared by reactive magnetron sputtering (RMS).

\subsubsection{Substrate/film interdiffusion}

A study of the possible interdiffusion between the SAXS Al-foil substrate and a$\mathrm{Si}: \mathrm{H}$ or a-Ge:H films has been completed using depth-profiling Auger electron spectroscopy ${ }^{39}$. 30-50 nm-thick a-Si:H and a-Ge:H films were deposited onto the $\mathrm{Al}$ foil substrates and annealed at various temperatures up to $600^{\circ} \mathrm{C}$. Little or no interdiffusion was found at or below temperatures of $400^{\circ} \mathrm{C}$, contrary to what is typically found by evaporating $\mathrm{Al}$ onto previously deposited a-Si:H films without breaking vacuum, where interdiffusion occurs at or below $200^{\circ} \mathrm{C}$. A native $\mathrm{Al}$-oxide layer about 15 to $30 \mathrm{~nm}$ thick on the Al-foil substrates apparently serves as an effective diffusion barrier until temperatures of $450-500^{\circ} \mathrm{C}$ are reached where both interdiffusion and crystallization occur. The latter was detected by Raman scattering ${ }^{39}$.

\subsubsection{Modeling of tilting effects}

Progress has been made in the modeling of the anisotropic SAXS that is observed by tilting a sample relative to the $\mathrm{x}$-ray beam. Assuming ellipsoidal-shaped voids, values of the aspect ratio of the axes can be adjusted for up to five distinct sizes of voids in 
order to fit two or more sets of SAXS curves obtained for different tilt angles. Fits to a set of a-Ge:H data suggest aspect ratios in the range from 2 to 6 . Details will be presented elsewhere ${ }^{30}$.

\section{ACKNOWLEDGEMENTS}

We are extremely grateful to the groups and individuals that have supplied all of the samples and all of the opto-electronic data needed for this research. The support of NREL through contract XG-1-10063-3 and the Electric Power Research Institute through Technical Agreement RP2824-05 is gratefully acknowledged. The technical support of NREL in the form of AES and EPMA measurements by Art Nelson, Amy Swartzlander-Franz and Alice Mason was important for our progress.

\section{REFERENCES}

1. N.M. Johnson, F.A. Ponce, R.A. Street, and R.J. Nemanich, Phys. Rev. B 35, 4166 (1987); N.M. Johnson, Physica B 170, 3 (1991).

2. C.C. Tsai, G.B. Anderson, and R. Thompson, J. Non-Cryst. Solids 137\&138, 673 (1991).

3. J.C. Knights and G. Lucovsky, CRC Crit. Rev. Solid State and Mats. Sci. 21, 211 (1980).

4. W. Paul, S.J. Jones, and W.A. Turner, Phil. Mag. B 63, 247 (1991).

5. H. Wagner and W. Beyer, Solid State Commun. 48, 585 (1983).

6. P.C. Taylor, in Semiconductors and Semimetals, vol. 21C: Hydrogenated Amorphous Silicon, ed. by J.I. Pankove (Academic, Orlando, 1984)

p. 99 and references therein.

7. Y.J. He, M. Hasegawa, R. Lee, S. Berko, D. Adler, and A.-L. Jung, Phys.

Rev. B 33, 5924 (1986).

8. M.B. Schubert and G.H. Bauer, Phil. Mag. B 62, 59 (1990).

9. P. Menna, A.H. Mahan, and R. Tsu, Proc. 19th IEEE PV Spec. Conf. (IEEE, New York, 1987) p.832.

10. S.J. Jones, Y. Chen, D.L. Williamson, and G.D. Mooney, Mat. Res. Soc. Symp. Proc. 258, 229 (1992).

11. Small Angle X-ray Scattering, ed. by O. Glatter and O. Kratky (Academic, New York, 1982).

12. D.L. Williamson, A.H. Mahan, B.P. Nelson, and R.S. Crandall, Appl. Phys. 
Lett. 55, 783 (1989).

13. L.H. Schwartz and J.B. Cohen, Diffraction from Materials (Springer-Verlag, Heidelberg, 1987) p.232.

14. A. Guinier and G. Fournet, Small Angle Scattering of X-rays (Wiley, New York, 1955).

15. S. Guha, J. Yang, Scott J. Jones, Yan Chen, and D.L. Williamson, Appl. Phys. Lett. 61, 1444 (1992).

16. D.L. Williamson, Y. Chen, S.J. Jones and G.D. Mooney, Annual Rep., Photovoltaic Subcontract Program FY 1991, NREL/TP-410-4724 (1992) p.1S.

17. S.J. Jones, Y. Chen, D.L. Williamson, U. Kroll, and P. Roca i Cabarrocas, J. Non-Cryst. Solids 164-166, 131 (1993).

18. R. Banerjee, S.N. Sharma, S. Chattopadhyay, A.K. Batabyal and A.K. Barua, J. Appl. Phys. 74, 4540 (1993).

19. S. Chattopadyay, S.N. Sharma, R. Banerjee, D.M. Bhusari, S.T. Kshirsagar, Yan Chen and D.L. Williamson, (submitted to J. Appl. Phys., 1994)

20. A.H. Mahan, Y. Chen, D.L. Williamson, and G.D. Mooney, J. Non-Cryst. Solids 137\&138, 65 (1991).

21. D.L. Williamson, S.J. Jones and Yan Chen, NREL Second Year Annual Report (1993).

22. Y. Chen, S.J. Jones, D.L. Williamson, S. Yang, N. Maley, and J.R. Abelson, Mat. Res. Soc. Symp. Proc. 258, 311 (1992).

23. S.J. Jones, Yan Chen, D.L. Williamson and G.D. Mooney, Mat. Res. Soc. Symp. Proc. 258, 229 (1992).

24. S.J. Jones, Y. Chen, D.L. Williamson, R. Zedlitz, and G. Bauer, Appl. Phys. Lett. 62, 3267 (1993).

25. J.P. Dismukes, L. Ekstrom and R.J. Paff, J. Phys. Chem. 68, 3021 (1964).

26. S. Muramatsu, T. Shimada, H. Kajiyama, K. Azuma, T. Watanabe, T. Kamiyama and K. Suzuki, Jpn. J. Appl. Phys. 28, L1092 (1989).

27. S. Muramatsu, S. Matsubara, T. Watanabe, T. Shimada, T. Kamiyama, and K. Suzuki, J. Non-Cryst. Solids 150, 163 (1992).

28. S.J. Jones, Y. Chen, D.L. Williamson, X. Xu, J. Yang, and S. Guha, Mat. Res. Soc. Symp. Proc. 297, 815 (1993).

29. A.H. Mahan B.P. Nelson, R.S. Crandall, and D.L. Williamson, IEEE Trans. Electron Devices 36, 2859 (1989).

30. S.J. Jones, Y. Chen, D.L. Williamson, P. Wickboldt, D. Pang, A.E. Wetsel, W. Paul and J.H. Chen (in preparation). 
31. J. Daey Ouwens, R.E.I. Schropp, W.F. van der Weg and D.I. Williamson submitted to PVSEC, Amsterdam, 1994.

32. J. Kakalios, R.A. Street and W.B. Jackson, Phys. Rev. Lett. 59, 1037 (1987).

33. R. Shinar, J. Shinar, H. Jia and X.-L Wu, Phys. Rev. B 47, 9361 (1993) and references therein.

34. J. Shinar, H. Jia, R. Shinar, Y. Chen and D.L. Williamson, submitted to Phys. Rev. (1994).

35. V. Gerold, in Small-Angle X-ray Scattering, ed: H. Brumberger (Gordon and Breach, New York, 1967) p. 277.

36. Yan Chen, Ph.D. Thesis, T-4492, Colorado School of Mines (1994).

37. L. Yang J. Newton and B. Fieselmann, Mat. Res. Soc. Symp. Proc. 149, 497 (1989).

38. M.B. Schubert and G.H. Bauer, Phil. Mag. B 62, 59 (1990).

39. S.J. Jones, A.B. Swartzlander-Franz, Y. Chen and D.L. Williamson, Mat. Res. Soc. Symp. Proc. 297, 1049 (1993).

\section{APPENDIX:}

\section{LIST of PUBLICATIONS from this RESEARCH}

A. "The structure of a-Si:H by small angle $\mathrm{x}$-ray scattering" A.H. Mahan, Y. Chen, D.L. Williamson and G.D. Mooney, J. Non-Cryst. Solids 137\&138, 65 (1991).

B. "Effect of microvoids on initial and light-degraded efficiencies of hydrogenated amorphous silicon alloy solar cells" S. Guha, J. Yang, Scott J. Jones, Yan Chen and D.L. Williamson, Appl. Phys. Lett. 61, 1444 (1992).

C. "Small-angle x-ray scattering from a-Si:H and a-SiC:H alloys prepared by reactive dc magnetron sputtering" Y. Chen, S.J. Jones, D.L. Williamson, S. Yang, N. Maley and J.R. Abelson, Mat. Res. Soc. Symp. Proc. 258, 311 (1992).

D. "Small-angle $\mathrm{x}$-ray scattering studies of glow-discharge-produced a-SiGe:H alloys" Scott J. Jones, Yan Chen, D.I. Williamson and G.D. Mooney, Mat. Res. Soc. Symp. Proc. 258, 229 (1992).

E. "Microstructure transition and degraded opto-electronic properties in amorphous SiGe:H alloys" S.J. Jones, Y. Chen, D.L. Williamson, R. Zedlitz and G. Bauer, Appl. Phys. Lett. 62, 3267 (1993). 
F. "Correlation of SAXS and solar cell performance of a-SiGe:H alloys" S.J. Jones, Y. Chen, D.L. Williamson, X. Xu, J. Yang and S. Guha, Mat. Res. Soc. Symp. Proc. 297, 815 (1993).

G. "Interdiffusion at a-Ge:H/Al and a-Si:H/Al interfaces" S.J. Jones, A.B. Swartzlander-Franz, Y. Chen and D.L. Williamson, Mat. Res. Soc. Symp. Proc. 297, 1049 (1993).

$\mathrm{H}$. "The effects of $\mathrm{Ar}$ and $\mathrm{He}$ dilution on the microstructure of a-Si:H detected by SAXS" S.J. Jones, Y. Chen, D.L. Williamson, U. Kroll and P. Roca i Cabarrocas, J. Non-Cryst. Solids 164-66, 131 (1993).

I. "Microstructure of a-Si:H, a-SiGe:H, and a-SiC:H Solar Cell Materials" D.L. Williamson, Y. Chen and S.J. Jones, AIP Conf. Proc. (in press, 1994).

J. "Short range order, microstructure and their correlation with light induced degradation in a-Si:H deposited at high growth rates by cathode heating technique" $\mathrm{S}$. Chattopadhyay, S.N. Sharma, R. Banerjee, D.M. Bhusari, S.T. Kshirsagar, Y. Chen and D.L: Williamson, submitted to J. Appl. Phys. (1994).

K. "Microvoid, $\mathrm{Si}, \mathrm{H}$, and $\mathrm{Al}$ dynamics in a-Si: $\mathrm{H} / \mathrm{Al}_{2} \mathrm{O}_{3} / \mathrm{Al}$ structures: a small-angle $\mathrm{x}$ ray scattering and infrared absorption study" J. Shinar, H. Jia, R. Shinar, Y. Chen and D.L. Williamson, submitted to Phys. Rev. (1994).

L. "The relation between film microstructure, plasma chemistry and the photoelectronic quality of a-Ge:H deposited by plasma enhanced chemical vapor deposition" S.J. Jones, Y. Chen, D.L. Williamson, P. Wickboldt, D. Pang, A.E. Wetsel, W. Paul and J.H. Chen (in preparation).

M. "Optimization of wide band gap a-SiC:H p $\mathrm{p}^{+}$-layers" J. Daey Ouwens, R.E.I. Schropp, W.F. van der Weg and D.L. Williamson (submitted to PVSEC, 1994). 
